\title{
The Labor Wedge as a Matching Friction
}

\author{
ANTON A. CHEREMUKHIN \\ AND PAULINA RESTREPO-ECHAVARRIA \\ RESEARCH DEPARTMENT \\ WORKING PAPER 1004
}




\title{
The Labor Wedge as a Matching Friction
}

\author{
Anton A. Cheremukhin and Paulina Restrepo-Echavarria *
}

July 22,2010

\begin{abstract}
The labor wedge accounts for a large fraction of business cycle fluctuations. This paper uses a search and matching model to decompose the labor wedge into three classes of labor market frictions and evaluate their role. We find that frictions to job destruction and bargaining commonly considered in the search literature are not helpful in explaining the labor wedge. We also identify an asymmetric effect of separation, bargaining and matching frictions on unemployment, as well as a potential solution to Shimer's puzzle.
\end{abstract}

JEL: E20, E32, J22, J63, J64.

Keywords:Labor Wedge, Business Cycles, Search and Matching

For the last 25 years, macro and labor economists have pointed to large cyclical variations in the relationship between the marginal rate of substitution between leisure and consumption and the marginal product of labor

*Anton Cheremukhin: Federal Reserve Bank of Dallas, 2200 N Pearl St, Dallas TX 75201, chertosha@gmail.com, 214-922-6785. Paulina Restrepo-Echavarria: Department of Economics, The Ohio State University, 410 Arps Hall, 1945 N High Street, Columbus OH 43210, paur@ucla.edu. Authors thank Andrew Atkeson, Gary Hansen, Richard Rogerson, Robert Shimer, Pierre-Olivier Weill, Mark Wright, three anonymous referees, as well as participants of SED 2008, LAMES 2008 and Monetary Economics Proseminar at UCLA for helpful comments. The authors are especially thankful to Roger Farmer, Christian Hellwig and Lee Ohanian for their time and suggestions. All errors are our own. The views expressed in this paper are those of the authors and do not necessarily reflect the views of the Federal Reserve Bank of Dallas or the Federal Reserve System. First draft: April 9, 2008. 
as an important feature of business cycles. In their business cycle accounting framework, Chari, Kehoe and McGrattan (2007) (CKM) label this relationship a "labor wedge" and argue that it accounts for $60 \%$ of output fluctuations.

In this paper we look at the labor wedge through the lens of a search and matching model. We decompose the labor wedge into three classes of labor market frictions modeled as exogenous separation, bargaining and matching shocks and use the business cycle accounting methodology to evaluate their quantitative importance. Our main finding is that imperfections in the job destruction and bargaining processes commonly considered in the search literature are not helpful in explaining the labor wedge.

Equilibrium search and matching models provide a natural framework for studying labor market frictions manifested by the labor wedge. Matching frictions are also a common way of introducing adjustment along the extensive margin into business cycle models. However, Shimer (2005a) pointed out that the matching friction itself works as a labor adjustment cost and alone cannot explain variations in the two key labor market variables: unemployment and vacancies.

In order to help solve this puzzle various additional frictions have been introduced into search and matching models. One class of frictions introduced by Mortensen and Pissarides (1994) is endogenous job destruction, which we capture using an exogenous shock to the rate at which workers are separated from their jobs. The other class of frictions proposed by Hall (2005a) and analyzed by Shimer (2010) replaces the Nash bargaining solution with a backward-looking wage-setting rule. In our model this form of wage stickiness is represented more generally by exogenous variations in the relative bargaining power of workers and firms. Finally, we introduce a third, residual source of frictions by allowing for exogenous variations in the efficiency of the matching process.

Our modeling approach augments the representative agent RBC model with a search and matching friction as in Merz (1995) and Andolfatto (1996). The standard assumption that labor is traded in a spot market is replaced by a search friction which puts an additional constraint on how much labor can be employed. The model endogenously determines the level of unemployment, the number of vacancies and the labor force participation rate as in Farmer and Hollenhorst (2006). To model the frictions mentioned above we introduce three shocks which jointly determine the labor wedge in the model: the separation shock, the matching shock and the bargaining shock. 
The separation shock represents the proportion of employed workers that get separated from their jobs every period. The matching shock represents the efficiency of the matching technology. The bargaining shock represents the proportions in which the lifetime surplus of a newly formed match is split between the worker and the firm and thus pins down wages.

To evaluate the relative importance of each shock we use the business cycle accounting methodology employed in Cole and Ohanian (2002) and CKM. For identification purposes in addition to three labor market shocks, our model includes a TFP shock, an investment shock and a government consumption shock. We use data on real GDP, consumption, investment, hours, unemployment and vacancies to recover the six shocks: TFP, investment, government consumption, separation, matching and bargaining. We use the model as a diagnostic tool and measure the contributions of each shock to each of the six variables by running a counterfactual exercise: we fit the shocks back into the model one at a time and all but one at a time.

Compared to the neoclassical growth model in our model it is difficult to directly apply the business cycle accounting methodology. First, in order to recover the exact values of the underlying shocks we would have to iterate over the solution of the model until we find a fixed point of a complicated system of forward-looking equations. Instead, we compute the first order approximation of the model around a stochastic trend and use the Kalman filter to recover the shocks. Second, there is substantial controversy on the values of many labor market parameters, so we use a Bayesian estimation strategy to recover them, and let the data speak for itself.

Our accounting exercise leads us to a striking conclusion: variations in job destruction and impediments to the bargaining process jointly account for less than 10 percent of variations in the labor wedge. More than 90 percent of variations in the labor wedge are attributed to the residual shock to matching efficiency. This implies that commonly used frictions, such as endogenous variations in job destruction and wage stickiness, do not play a significant role in determining the labor wedge.

Our results indicate that a labor market friction responsible for variations in the labor wedge must be isomorphic to changes in matching efficiency. This broad class of frictions includes variations in per capita costs associated with creating jobs, variations in time and effort devoted to search by unemployed workers, variations in the level of congestion and in the degree of competition between peers characterizing the matching process.

Apart from the main result that shocks to matching efficiency play a lead- 
ing role in explaining the labor wedge, accounting for more than $90 \%$ of its variation, our results have two main implications. First, both job creation and job destruction shocks play an important role in output and unemployment fluctuations. This last result is relevant for the debate between Shimer (2005b) and Fujita and Ramey (2007) on whether job destruction or job creation is more important for fluctuations in output and unemployment. We find that both job destruction (separation) and job creation (bargaining and matching) shocks play a role, but at different points in time. At the beginning of a recession a decline in TFP coincides with an increase in the separation rate. As unemployment increases, the reservation value (threat-point) of the workers falls while an increase in the bargaining power of workers keeps the wage fairly constant. The corresponding decrease in the bargaining power of the firms leads to a decline in vacancies. Later the efficiency of the matching process falls, keeping unemployment at a high level. Thus, understanding the causes of excessive job destruction at the beginning of recessions, as well as sources of wage rigidity and insufficient matching during the recovery are equally important for understanding the behavior of the labor market.

The second implication of our results is a potential solution to Shimer's puzzle. Shimer $(2005 a)$ pointed out that standard Mortensen-Pissaridestype models are incapable of simultaneously generating high volatility of unemployment and vacancies and low volatility of wages. Our model while matching series for unemployment and vacancies by construction, predicts a path for wages which matches remarkably well the behavior of wages in the data. The fact that we match the volatility of wage data without using it in the estimation procedure, both serves as an over-identifying restriction on our empirical exercise ${ }^{1}$, and stresses the importance of changes in the outside option of workers as the main driving force behind the variations in bargaining power. Hall (2005b) suggested that changes in the bargaining power can be generated by fluctuations in the marginal product of labor when wages are sticky. Our results show that in order to fit the data, additional significant fluctuations in the outside option of workers are necessary.

The paper is organized as follows. Section 2 lays out the theoretical framework and introduces the six shocks, Section 3 describes the methodology we use to estimate the model and recover the shocks, Section 4 explains

\footnotetext{
${ }^{1}$ Note that the ability of a search model to match volatilities of unemployment and vacancies does not automatically imply matching the behavior of wages, as shown by Lubik (2009)
} 
the results and Section 5 concludes.

\section{Theoretical Framework}

This section lays out the setup of the model. We modify the standard one sector real business cycle model by adding a search technology for moving labor between productive activities and leisure. We assume that the economy is populated by a continuum of families. Each family operates a backyard technology and completely insures its members against variations in their labor incomes. Members of a family cannot work in their own backyard, but can be employed in two market activities: head-hunting which is competitive and a productive activity where the wage is set according to a specific wagesetting rule.

\section{$1.1 \quad$ Model}

The economy faces six exogenous shocks. A total factor productivity (TFP) shock $A_{t}$, an investment specific technology shock $T_{t}$, a government expenditure shock $G_{t}$, a shock to the separation rate of employment $\delta_{L t}$, a shock to matching efficiency $B_{t}$ and a shock to the bargaining power of workers $\phi_{t}$. This last shock $\phi_{t}$ represents the fraction of the lifetime surplus of the match that goes to the worker, hence, as we will show later on, $\phi_{t}$ determines the wage $w_{t}$ in the productive sector.

At the beginning of period $t$ values of shocks $A_{t}, T_{t}, \delta_{L t}, G_{t}, B_{t}, \phi_{t}$, capital $K_{t}$, labor supply $L_{t-1}^{s}$ and demand $L_{t-1}^{d}$, the job finding and vacancy filling rates are given. The head of each family decides how many members $V_{t}^{s}$ to send to look for a head-hunting job and how many members of other families $V_{t}^{d}$ to hire in the head-hunting market to search for unemployed workers to fill in positions in the backyard firm. Each head-hunter represents one vacancy and is paid a wage $q_{t}$.

The head of the family also decides how many members $L_{t}^{s}$ to send to work in productive activities and how many members of other families $L_{t}^{d}$ to employ to operate her own backyard technology. Finally, the head of the family assigns $U_{t}$ members to apply for jobs in other families' backyards, allocates resources to consumption $C_{t}$ of its members and invests into capital $K_{t+1}$ next period.

We introduce head-hunters into the model in order to measure costs of 
searching for a worker and costs of searching for a job in the same units of disutility of labor. We distinguish between labor demand and supply in both markets in order to derive shadow prices of both types of employment and compute the value of a match.

Each family head maximizes the expected lifetime utility of its members (1), subject to a budget constraint (2) and labor supply and demand accumulation constraints (3) and (4):

$$
\begin{gathered}
\max _{\left\{C_{t}, L_{t}^{s}, L_{t}^{d}, V_{t}^{s}, V_{t}^{d}, U_{t}, K_{t+1}\right\}} E_{t} \sum_{t=0}^{\infty} \beta^{t} U\left(C_{t}, L_{t}^{s}, V_{t}^{s}, U_{t}\right) \\
C_{t}+\frac{K_{t+1}-\left(1-\delta_{K}\right) K_{t}}{T_{t}}+G_{t} \leq A_{t} F\left(K_{t}, L_{t}^{d}\right)+w_{t}\left(L_{t}^{s}-L_{t}^{d}\right)+q_{t}\left(V_{t}^{s}-V_{t}^{d}\right) \\
L_{t}^{s}=\left(1-\delta_{L t}\right) L_{t-1}^{s}+U_{t} \frac{\bar{M}_{t}}{\bar{U}_{t}} \\
L_{t}^{d}=\left(1-\delta_{L t}\right) L_{t-1}^{d}+V_{t}^{d} \frac{\bar{M}_{t}}{\bar{V}_{t}},
\end{gathered}
$$

where $\bar{M}_{t}$ is the total number of matches formed in the economy in period $t$. In equation (3), labor supply in period $t$ depends on last period's labor supply minus the number of workers that got separated from their job plus the new formed matches. The separation rate $\delta_{L t}$ denotes the exogenously given rate at which workers are separated from their jobs and captures the various frictions leading to variations in job destruction over the cycle. The term $\frac{\bar{M}_{t}}{\bar{U}_{t}}$ stands for the job finding rate and represents the increase in employment when there is one more individual searching for a job $\left(U_{t}\right.$ increases by one unit). In equation (4), labor demand accumulates in the same way as labor supply with the difference that the term $V_{t}^{d} \frac{\bar{M}_{t}}{\bar{V}_{t}}$ is the vacancy filling rate times the number of head-hunters demanded and means that for every new individual that works as a head-hunter $V_{t}^{d}$, the stock of employed workers increases by $\frac{\bar{M}_{t}}{\bar{V}_{t}}$.

The markets for labor and head-hunting clear when $L_{t}^{s}=L_{t}^{d}=L_{t}$ and $V_{t}^{s}=V_{t}^{d}=V_{t}$. The law of motion of aggregate employment satisfies:

$$
L_{t}=\left(1-\delta_{L t}\right) L_{t-1}+M_{t}
$$

and in equilibrium $\bar{U}_{t}=U_{t}, \bar{V}_{t}=V_{t}$ and

$$
\bar{M}_{t}=M_{t}=B_{t} M\left(U_{t}, V_{t}\right)
$$


In equation (6) $B_{t}$ represents the efficiency of the matching technology, determining the number of matches formed for each combination of the numbers of workers and head-hunters seeking for a match. The resource constraint and production function are given by

$$
\begin{gathered}
C_{t}+\frac{1}{T_{t}}\left(K_{t+1}-\left(1-\delta_{K}\right) K_{t}\right)+G_{t}=Y_{t}, \\
Y_{t}=A_{t} F\left(K_{t}, L_{t}^{d}\right) .
\end{gathered}
$$

We derive the optimality conditions of the model:

$$
\begin{gathered}
\frac{1}{T_{t}}=\beta E_{t} \frac{U_{C_{t+1}}^{\prime}}{U_{C_{t}}^{\prime}}\left(A_{t+1} F_{K_{t+1}}^{\prime}\left(K_{t}, L_{t}\right)+\frac{1}{T_{t+1}}\left(1-\delta_{K}\right)\right) \\
w_{t}+\frac{U_{L_{t}}^{\prime}}{U_{C_{t}}^{\prime}}=\mu_{t}-\beta E_{t}\left(\frac{U_{C_{t+1}}^{\prime}}{U_{C_{t}}^{\prime}} \mu_{t+1}\left(1-\delta_{L t+1}\right)\right) \\
A_{t} F_{L_{t}}^{\prime}\left(K_{t}, L_{t}\right)-w_{t}=\eta_{t}-\beta E_{t}\left(\frac{U_{C_{t+1}}^{\prime}}{U_{C_{t}}^{\prime}} \eta_{t+1}\left(1-\delta_{L t+1}\right)\right) \\
\frac{U_{V_{t}}^{\prime}}{U_{C_{t}}^{\prime}}+q_{t}=0 \\
\eta_{t} \frac{M_{t}}{V_{t}}-q_{t}=0 \\
-\frac{U_{U_{t}}^{\prime}}{U_{C_{t}}^{\prime}}=\mu_{t} \frac{M_{t}}{U_{t}}
\end{gathered}
$$

In the equations above $\mu_{t}$ is the Lagrange multiplier associated with the labor supply accumulation constraint and $\eta_{t}$ is the Lagrange multiplier associated with the labor demand accumulation constraint, both measured in units of marginal utility of consumption. Since $T_{t}, A_{t}, \delta_{L t}, G_{t}$ and $B_{t}$ are exogenous, we have a system of ten equations and eleven variables, $\left\{K_{t+1}, L_{t}, C_{t}, M_{t}, Y_{t}, V_{t}, U_{t}, \mu_{t}, \eta_{t}, w_{t}, q_{t}\right\}$. The model is missing an equilibrium condition because equations (10) and (11) determine two different ways of moving labor between leisure and employment in productive activities and there is only one price $w_{t}$. Therefore, we introduce a bargaining shock to close the model. 


\subsection{Introducing Bargaining Shocks}

Note that equations (10) and (11) can be iterated forward to solve for the corresponding multipliers:

$$
\begin{gathered}
\eta_{t}=A_{t} F_{L_{t}}^{\prime}\left(K_{t}, L_{t}\right)-w_{t}+E_{t} \sum_{s=t+1}^{\infty} \beta^{s-t}\left(A_{s} F_{L_{s}}^{\prime}\left(K_{s}, L_{s}\right)-w_{s}\right) \prod_{k=t+1}^{s}\left(1-\delta_{L k}\right) \\
\mu_{t}=\frac{U_{L_{t}}^{\prime}}{U_{C_{t}}^{\prime}}+w_{t}+E_{t} \sum_{s=t+1}^{\infty} \beta^{s-t}\left(\frac{U_{L_{s}}^{\prime}}{U_{C_{s}}^{\prime}}+w_{s}\right) \prod_{k=t+1}^{s}\left(1-\delta_{L k}\right)
\end{gathered}
$$

The Lagrange multiplier in the labor demand (supply) accumulation equation is the expected sum of instantaneous marginal values of the match for the representative firm (worker), discounted and adjusted for the probability of the match being dissolved in any given period.

Similarly, the sum $\mu_{t}+\eta_{t}$ of the two Lagrange multipliers can be interpreted as the lifetime surplus of the match - an expected sum of instantaneous marginal values of the match discounted and adjusted for the probability of the match being dissolved in any given period.

$\Gamma_{t}=A_{t} F_{L_{t}}^{\prime}\left(K_{t}, L_{t}\right)+\frac{U_{L_{t}}^{\prime}}{U_{C_{t}}^{\prime}}+E_{t} \sum_{s=t+1}^{\infty} \beta^{s-t}\left(A_{s} F_{L_{s}}^{\prime}\left(K_{s}, L_{s}\right)+\frac{U_{L_{s}}^{\prime}}{U_{C_{s}}^{\prime}}\right) \prod_{k=t+1}^{s}\left(1-\delta_{L k}\right)$

A standard way to close search and matching models is to assume that the worker and the firm use Nash bargaining over the wage and split the surplus in constant proportions. However, Shimer (2005a) and Hall (2005b) argue that for a Mortensen-Pissarides-type model to fit the data one needs variations in the bargaining power. In order to incorporate such a friction we close the model by assuming that the surplus $\Gamma_{t}$ is split between the worker and the firm according to a time-varying rule. ${ }^{2}$

We define a variable $\phi_{t}$ to represent the fraction of the lifetime surplus of the match going to the worker, and $\left(1-\phi_{t}\right)$ the fraction of the lifetime surplus of the match going to the firm. We assume that $\eta_{t}=\left(1-\phi_{t}\right) \Gamma_{t}$ and $\mu_{t}=\phi_{t} \Gamma_{t}$. Hence, we refer to $\phi_{t}$ as the bargaining power of the worker as well as the bargaining shock. Notice that allocations are economically inefficient

\footnotetext{
${ }^{2}$ For a more general description of how we construct the bargaining shock see Appendix A.
} 
whenever $\phi_{t}$ is different from the elasticity of the matching function with respect to the number of unemployed. ${ }^{3}$

Substituting the bargaining shock and the lifetime surplus of the match into equations (10), (11), (12), (13) and (14) yields:

$$
\begin{gathered}
\Gamma_{t}=A_{t} F_{L_{t}}^{\prime}\left(K_{t}, L_{t}\right)+\frac{U_{L_{t}}^{\prime}}{U_{C_{t}}^{\prime}}+\beta E_{t}\left(\frac{U_{C_{t+1}}^{\prime}}{U_{C_{t}}^{\prime}} \Gamma_{t+1}\left(1-\delta_{L t+1}\right)\right) \\
\left(1-\phi_{t}\right) \Gamma_{t} \frac{M_{t}}{V_{t}}=-\frac{U_{V_{t}}^{\prime}}{U_{C_{t}}^{\prime}} \\
\phi_{t} \Gamma_{t} \frac{M_{t}}{U_{t}}=-\frac{U_{U_{t}}^{\prime}}{U_{C_{t}}^{\prime}}
\end{gathered}
$$

Equation (18) governs the behavior of the total value of the match. Today's value is equal to the instantaneous gain from a newly formed match plus the future value, discounted and adjusted for the possibility of being destroyed tomorrow.

Equations (19) and (20) equate the marginal benefits and marginal costs of head-hunting and searching for a job respectively and thus pin down vacancies and unemployment. Equations (21) and (22) below determine the real wage and the discount factor for labor:

$$
\begin{gathered}
\left(w_{t}+\frac{U_{L_{t}}^{\prime}}{U_{C_{t}}^{\prime}}\right)=\frac{\phi_{t}-\beta E_{t}\left(\frac{U_{C_{t+1}}^{\prime}}{U_{C_{t}}^{\prime}} \phi_{t+1} \Psi_{t+1}\right)}{1-\beta E_{t}\left(\frac{U_{C_{t+1}}^{\prime}}{U_{C_{t}}^{\prime}} \Psi_{t+1}\right)}\left(A_{t} F_{L_{t}}^{\prime}\left(K_{t}, L_{t}\right)+\frac{U_{L_{t}}^{\prime}}{U_{C_{t}}^{\prime}}\right) \\
\Psi_{t+1}=\beta \frac{\Gamma_{t+1}}{\Gamma_{t}}\left(1-\delta_{L t+1}\right)
\end{gathered}
$$

A competitive equilibrium of the model economy is a solution to equations (5)-(9), (12), and (18)-(22) where $\left\{K_{t+1}, C_{t}, L_{t}, V_{t}, U_{t}, \Gamma_{t}, w_{t}, q_{t}, \Psi_{t}, Y_{t}, M_{t}\right\}$ are endogenous variables and $\left\{A_{t}, T_{t}, \delta_{L t}, G_{t}, B_{t}, \phi_{t}\right\}$ are the exogenous shocks of the model. The exogenous variables behave according to stochastic processes to be defined later.

\footnotetext{
${ }^{3}$ See Hosios (1990) for a detailed discussion.
} 


\subsection{Identifying assumptions}

Most of the functional forms we use are standard in the literature. We assume that the production function is Cobb-Douglas with constant returns to scale:

$$
F(K, L)=K^{\alpha} L^{1-\alpha}
$$

We assume that the matching function is also Cobb-Douglas and consistent with constant returns to scale:

$$
M(U, V)=U^{\theta} V^{1-\theta}
$$

We postulate a utility function consistent with a balanced growth path and where fractions of time spent head-hunting and searching for a job enter symmetrically with the time spent on the production activity:

$$
U(C, L, U, V)=\log C-\chi \frac{(L+V+U)^{1+\gamma}}{1+\gamma}
$$

The functional form for hours is the only non-standard assumption we make. It implies that workers get the same disutility from working in productive activities as when searching for a job or head-hunting. This assumption may seem somewhat extreme, but we assume that although individuals spend only a few hours per week searching for a job, they also spend time in other activities that generate disutility: in expanding their network by making phone calls, getting technical training, continuing their education, helping their relatives or working in home production.

Another implication of this assumption is that the costs of searching for a job from the point of view of an unemployed worker and of a firm with a vacant position are equalized. While micro data sheds little light on how to discipline these costs, this assumption delivers a clear-cut interpretation of the shocks. In the decomposition we perform this assumption distinguishes the variations in labor market variables attributed to the bargaining shock from those attributed to the matching shock. It insures that any variations in the search costs on the worker and firm sides show up as variations in the matching efficiency shock, while variations in the wage-setting practices show up as the bargaining shock.

In the decomposition we perform, this utility function also affects the behavior of the reservation value of the workers and search costs. The parameter $\gamma$ determines how much the labor costs fall as families spend less time in the labor market. 
Given these functional forms and stochastic processes for the shocks, to be explained later, the shocks are uniquely identified. Appendix A explains step by step how given data on output, consumption, investment, hours, unemployment and vacancies one can recover the shocks.

\subsection{Decomposing the Labor Wedge}

Here we explore how the three labor market shocks affect the labor wedge and jointly determine its behavior. Combining equations (19) and (20) and substituting in the functional forms we get:

$$
\begin{gathered}
\frac{1-\phi_{t}}{\phi_{t}}=\frac{V_{t}}{U_{t}} \\
\Gamma_{t}=-\frac{U_{U_{t}}^{\prime} U_{t}+U_{V_{t}}^{\prime} V_{t}}{U_{C_{t}}^{\prime} M_{t}}=M R S_{t} \frac{1}{B_{t} \phi_{t}^{\theta}\left(1-\phi_{t}\right)^{1-\theta}}
\end{gathered}
$$

Substituting these into equation (18) moving everything except the marginal product to one side and rearranging we get:

$$
\frac{M P_{t}}{M R S_{t}}-1=\frac{1}{B_{t} \phi_{t}^{\theta}\left(1-\phi_{t}\right)^{1-\theta}}-\beta E_{t} \frac{U_{C_{t+1}}^{\prime}}{U_{C_{t}}^{\prime}} \frac{M R S_{t+1}}{M R S_{t}} \frac{1-\delta_{L t+1}}{B_{t+1} \phi_{t+1}^{\theta}\left(1-\phi_{t+1}\right)^{1-\theta}}
$$

Equation (28) shows how the separation, bargaining and matching shocks together form a connection between the marginal product of labor and the marginal rate of substitution between leisure and consumption: the labor wedge.

Note that when the separation shock is non-persistent and since only its expectation affects the labor wedge, it cannot play a significant quantitative role. This is true because agents expect the separation rate next period to be in the neighborhood of the steady-state. However, in general both matching and bargaining shocks can have a significant effect on the labor wedge.

Changes in the matching shock are always going to matter, while the importance of the bargaining shock depends on the relationship between $\theta$ and the steady-state value of $\phi_{t}$. Notice that an increase in the bargaining power of workers always leads to a corresponding decrease in the bargaining power of firms and the total effect of the term $\phi_{t}^{\theta}\left(1-\phi_{t}\right)^{1-\theta}$ depends on $\theta$. 
Equation (29) states that if $\phi_{s s}$ is equal to $\theta$ then the effects of the bargaining shocks are negligible.

$$
\left.\frac{\partial \phi_{t}^{\theta}\left(1-\phi_{t}\right)^{1-\theta}}{\partial \phi_{t}}\right|_{\phi_{t}=\theta}=\left.\left(\frac{\theta}{\phi_{t}}-\frac{1-\theta}{1-\phi_{t}}\right) \phi_{t}^{\theta}\left(1-\phi_{t}\right)^{1-\theta}\right|_{\phi_{t}=\theta}=0
$$

This implies that even when the Hosios condition does not hold exactly, but holds on average, changes in the bargaining power do not significantly

affect the labor wedge. In fact the values of $\theta$ and $\phi_{s s}$ have to be very far apart for the bargaining power to have a substantial effect on the labor wedge. Therefore it is natural to expect matching shocks to play a dominant role in determining the behavior of the labor wedge.

\section{Methodology}

This section describes the details of the estimation procedure. Our estimation strategy is different from that of CKM in three dimensions. First, because computing the shocks exactly involves solving a complicated fixed point problem, we apply the Kalman filter to a linearized version of the model to compute the shocks approximately.

Second, though some of the parameters can be calibrated, others have no analogs in the literature. In order to let the data choose appropriate values for these parameters we apply a Bayesian estimation strategy, which uses the Kalman filter results from the first step and iterates over the parameter space using Markov Chain Monte-Carlo (MCMC) methods.

Finally, estimation results can depend significantly (see Cogley and Nason (1995)) on the way the data is pre-filtered. In order to avoid certain filtering biases we minimize the extent to which we alter the data. We embed the trends into the model. We describe in detail a procedure of detrending the model around a non-stationary stochastic trend, which we borrow from Fernandez-Villaverde and Rubio-Ramirez (2007).

\subsection{Processes for the shocks}

In the data real output, consumption and investment are nonstationary even with respect to a log-linear trend. To make the data comparable to the model, 
the business cycle literature commonly uses the Hodrick-Prescott (HP) filter. However, Cogley and Nason (1995) and Canova (1998) show that the use of the filter introduces significant biases into the data by amplifying businesscycle frequencies even if it does not have any. To avoid prefiltering the data we follow the approach presented in Fernandez-Villaverde and Rubio-Ramirez (2007) and assume random walks for the two processes that are commonly thought to be extremely persistent: the TFP and investment shocks $A_{t}$ and $T_{t}^{4}$.

We denote $a_{s s}$ the mean growth rate of TFP, and $\tau_{s s}$ the mean growth rate of the investment-specific technology. We assume that the rest of the shocks follow first-order autoregressive processes.

We denote the separation rate in steady-state $\delta_{L s s}$, the fraction of hours spent on head-hunting in steady-state $B_{s s}$, the average bargaining power which determines the vacancy-unemployment ratio $\phi_{s s}$, and the steady-state fraction of GDP consumed by the government $g_{s s}$. Also $\sigma$. and $\rho$. denote the standard deviations and autocorrelations of the shocks. All innovations are assumed to be standard normal ${ }^{5}$. We do not put restrictions on the correlations of these innovations ${ }^{6}$.

\subsection{Detrending}

Here we describe how to detrend the model with respect to a pair of nonstationary trends. From the optimality conditions of the model we can see that all variables except capital grow at a factor $\left(a_{s s} \tau_{s s}^{\alpha}\right)^{\frac{1}{1-\alpha}}$. Then, if we take the first differences of the TFP and investment shocks by defining $a_{t}=\frac{A_{t}}{A_{t-1}}=a_{s s} \exp \left(\sigma_{A} \varepsilon_{A t}\right), \tau_{t}=\frac{T_{t}}{T_{t-1}}=\tau_{s s} \exp \left(\sigma_{T} \varepsilon_{T t}\right)$, we can derive an aggregate trend $Z_{t}^{1-\alpha}=A_{t} T_{t}^{\alpha}$, which will be common to all the variables except capital. Hence, we can define detrended variables of the form: $x_{t}=\frac{X_{t}}{Z_{t-1}}$. Capital grows at a factor $\left(a_{s s} \tau_{s s}\right)^{\frac{1}{1-\alpha}}$, so it is detrended as follows: $k_{t+1}=\frac{K_{t+1}}{Z_{t} T_{t}}$.

Similarly to the result of King et. al. (1988) given separability of the utility function, we need to assume logarithmic utility for there to exist a balanced growth path. This will not affect our results since Hansen (1986)

\footnotetext{
${ }^{4}$ In fact using an HP-filter does not change any of our main results.

${ }^{5}$ We focus on realizations of $\phi_{t}$ and $\delta_{L t}$ which are in the interval $[0,1]$.

${ }^{6} \mathrm{We}$ estimated the model under different correlation structures and this assumption does not affect any of our results.
} 
has shown that quantitatively the degree of risk aversion has almost no effect on the behavior of quantities in real business cycle models.

Appendix B shows the resulting detrended equilibrium conditions of the model. This model possesses a unique steady-state - we describe the algorithm of computing the steady-state in Appendix B as well. We then linearize the model around the steady-state, compute the state-space representation and estimate the parameters.

\subsection{Data}

We use six variables in our estimation procedure: 1) real per capita GDP, 2) real per capita nondurable consumption expenditures, 3) real per capita gross private domestic investment (including durable consumption), 4) an index of aggregate weekly per capita hours worked in private industries, 5) the unemployment rate and 6) the Conference Board help-wanted advertising index as a proxy for vacancies.

All data are seasonally adjusted. Monthly data is averaged to make it quarterly. We divide by population to obtain per capita values. This corresponds to modeling the economy using a representative household/firm. We remove an extremely low frequency trend from hours, unemployment and vacancies, using an hp-filter with a smoothing parameter 100000 (we follow Shimer $(2005 a))$. This removes long-run secular trends, which are a result of demographic and other factors unrelated to business cycles. We normalize the resulting detrended indexes of hours and vacancies to one on average. We take logs of GDP, consumption and investment, and then take the first difference. All data we use is for the period 1964:I-2007:III.

To be able to estimate the model we need to add six measurement equations corresponding to the six variables that we observe. Since the data for real output, consumption and investment are modeled as nonstationary, we take the first differences of the data to make it comparable to the model. In addition, the definition of output in our model includes time spent headhunting. In the real economy firms are paying head-hunters a wage and it is measured as part of GDP. To account for this, we derive the price of time spent head-hunting, multiply it by the amount of time spent in this activity and include the product in our definition of GDP.

Hours in our model correspond to the total time spent on the productive activity and head-hunting. This index corresponds closely to total employment $L_{t}+V_{t}$, since most of the cyclical variation in hours is on the extensive 
margin (see Gertler, Sala, Trigari (2008) and Hall (2005b)) ${ }^{7}$. Due to the above correspondence between hours and employment, the time spent by the representative agent searching for a job as a fraction of the total time spent in the labor market $\frac{U_{t}}{L_{t}+V_{t}+U_{t}}$ corresponds to the number of people searching for a job as a fraction of people participating in the labor market - the unemployment rate. Changes in the help-wanted advertising index proxy changes in the number of vacancies $V_{t}$ posted by firms.

\subsection{Calibration and Estimation}

Our model has 9 structural parameters and 13 parameters that characterize the shocks. The scale parameter $L_{s s}$ does not affect the log-linearized representation of the model. There are three parameters standard to the business-cycle literature that we calibrate. We set the share of capital in the Cobb-Douglas production function $\alpha$ to 0.34 , the discount factor $\beta$ to 0.99 , the depreciation rate $\delta_{K}$ to $2.5 \%$ per quarter. We set the steady-state value of the government shock to $22 \%$ of GDP, the average value in the data. We also set the elasticity of matches to unemployment $\theta$ to 0.7 , the value used by Shimer (2005a); this falls within the range of values plausible from a microeconomic perspective reported by Blanchard and Diamond (1989). We calibrate this parameter because it is not well-identified. We find that this value of $\theta$ helps us match the volatility of wages, a series which is not used in our estimation procedure.

From the average growth rates of investment, consumption and output we infer the means of innovations to TFP and investment shocks. We calibrate them to be 0.16 percent and 0.12 percent per quarter respectively. Table 1 summarizes the calibrated parameters.

We estimate the model using Bayesian methods (see An and Schorfheide (2007)). Linearized equations of the model combined with the linearized measurement equations form a state-space representation of the model. We apply the Kalman filter to compute the likelihood of the data given the model and to obtain smoothed estimates of the innovations to the shocks. We combine the likelihood function $L\left(Y^{\text {Data }} \mid p\right)$, where $p$ is the parameter vector, with the priors $\pi_{0}(p)$ to obtain the posterior distribution of the parameters $\pi\left(p \mid Y^{\text {Data }}\right)=L\left(Y^{\text {Data }} \mid p\right) \pi_{0}(p)$. Draws from the posterior distribution are

\footnotetext{
${ }^{7}$ We have estimated the model using data on total employment instead of total hours. Most of our results remain unchanged. We prefer using hours so that we can directly compare our results to CKM.
} 


\begin{tabular}{|c|c|c|c|c|c|c|}
\hline$\alpha$ & $\beta$ & $\delta_{K}$ & $g_{s s}$ & $\theta$ & $a_{s s}$ & $\tau_{s s}$ \\
\hline 0.34 & 0.99 & 0.025 & 0.22 & 0.7 & 1.0016 & 1.0012 \\
\hline
\end{tabular}

Table 1: Calibrated parameters

\begin{tabular}{|c|ccc|ccc|}
\hline Parameter & \multicolumn{3}{|c|}{ Prior } & \multicolumn{3}{c|}{ Posterior } \\
\hline & Distribution & Mean & S.D. & Mean & {$[5 \%$} & $95 \%]$ \\
\hline$\gamma$ & log Normal & 0.00 & 2.000 & 3.54 & {$[2.97$,} & $4.43]$ \\
$\delta_{L s s}$ & Gamma & 0.02 & 0.010 & 0.036 & {$[0.030$,} & $0.043]$ \\
$\omega_{s s}$ & Gamma & 0.35 & 0.150 & 0.61 & {$[0.49$,} & $0.73]$ \\
$\phi_{s s}$ & Beta & 0.50 & 0.200 & 0.56 & {$[0.49$,} & $0.64]$ \\
\hline
\end{tabular}

Table 2: Prior and posterior distributions of structural parameters

generated using the Markov-Chain Monte-Carlo (MCMC) algorithm. We use the Random-Walk Metropolis-Hastings implementation.

Table 2 reports the prior and posterior distributions of each structural parameter. The parameter $\omega_{s s}$ represents the steady-state job finding rate. We estimate the elasticity of the utility function $\gamma$ with respect to labor to be $3.54^{8}$. This high elasticity leads to large variations in the value of non-market activity to be discussed later.

We estimate the steady-state separation rate to be $3.6 \%$. This is much lower than Shimer's (2005a) quarterly estimate of the separation probability for employed workers. This difference comes from the fact that our separation rate corresponds to the average fraction of jobs permanently destroyed every quarter. In additional to the permanent destruction an estimate of the separation rate would include a component capturing short-term turnover between employment and unemployment and a large job-to-job transition component. Assuming (following Shimer) that the average job finding rate is $40 \%$ per month and the separation rate to be $3 \%$ per month, the effective number of people becoming and staying unemployed until next quarter should be around 2-3\%, which is consistent with our estimate. Our model implies a $61 \%$ average job-finding rate which is also comparable to Shimer's estimates.

We estimate the steady-state bargaining power $\phi_{s s}$ to be 0.56 , which is close to the value of 0.5 common in the literature (see Mortensen and Nagypal

\footnotetext{
${ }^{8}$ We assume a log normal distribution with the support on $[-1,+\infty)$, which is equivalent to $\log (\gamma+1)$ being normally distributed.
} 


\begin{tabular}{|c|ccc|ccc|}
\hline Parameter & \multicolumn{3}{|c|}{ Prior } & \multicolumn{3}{c|}{ Posterior } \\
\hline & Distribution & Mean & S.D. & Mean & {$[5 \%$,} & $95 \%]$ \\
\hline$\rho_{S}$ & Beta & 0.50 & 0.20 & 0.72 & {$[0.65$,} & $0.80]$ \\
$\rho_{M}$ & Beta & 0.80 & 0.10 & 0.86 & {$[0.84$,} & $0.88]$ \\
$\rho_{B}$ & Beta & 0.80 & 0.10 & 0.98 & {$[0.96$,} & $0.99]$ \\
$\rho_{G}$ & Beta & 0.80 & 0.10 & 0.90 & {$[0.87$,} & $0.92]$ \\
$\sigma_{A}$ & IGamma & 0.02 & 0.010 & 0.0067 & {$[0.0062$,} & $0.0073]$ \\
$\sigma_{T}$ & IGamma & 0.02 & 0.010 & 0.0074 & {$[0.0067$,} & $0.0081]$ \\
$\sigma_{S}$ & IGamma & 0.25 & 0.100 & 0.180 & {$[0.154$,} & $0.212]$ \\
$\sigma_{M}$ & IGamma & 0.10 & 0.050 & 0.087 & {$[0.070$,} & $0.099]$ \\
$\sigma_{B}$ & IGamma & 0.10 & 0.050 & 0.046 & {$[0.038$,} & $0.055]$ \\
$\sigma_{G}$ & IGamma & 0.08 & 0.040 & 0.025 & {$[0.022$,} & $0.028]$ \\
\hline
\end{tabular}

Table 3: Prior and posterior distributions of shock parameters

(2007) and Hall $(2005 b))$. The estimates of the two parameters $\omega_{s s}$ and $\phi_{s s}$ jointly imply, that the average reservation utility is approximately $80 \%$ of the worker's marginal product. This moves in the direction of Hagedorn and Manovsky's (2008) calibration of the value of non-market activity (0.95) and is higher than the calibration of Hall (0.4). Our estimate of the parameter $\omega_{s s}$ also pins down the ratio of time spent head-hunting to time spent in the production activity which turns out to be $4 \%$. Taking into account the proximity of the shadow prices of different allocations of time, this mimics closely Hagedorn and Manovsky's estimate of the cost of vacancies being $3-4.5 \%$ of the quarterly wage. However, unlike their model, most of the variation in the bargaining set comes from variations in the value of nonmarket activity, not the marginal product.

Table 3 reports the prior and posterior distributions of the persistence and variance parameters of the shocks. The separation rate is the least persistent with a quarterly autoregressive parameter equal to 0.72 . The matching and government shocks are more persistent, but still significantly less persistent than a random walk. The persistence of government consumption is 0.90 exactly like in the data. The bargaining shock is close to a random walk. See Figures in Appendix $\mathrm{C}$ to compare the prior and posterior distributions of the parameters. Our model explains $100 \%$ of the variation in the six variables and thus provides a decomposition we need for the business cycle accounting exercise. 


\section{Results}

We divide our results into three parts. In the first part we show that the labor wedge can be interpreted as the instantaneous welfare gain from a new match. This surplus shrinks in good times and expands in recessions. The second part constitutes the descriptive core of our results. We describe the behavior of the recovered shocks, measure their contributions and evaluate their effects on the labor wedge, output and unemployment. We address the debate between Fujita and Ramey (2007) and Shimer (2005a) on whether job destruction or job creation is more important for fluctuations in unemployment and output. The last part of this section constitutes the analytic core of our results. It describes the mechanisms driving our results. We show the predicted wage rate, compare it to the data and explain why the model can solve Shimer's puzzle.

\subsection{Behavior and Interpretation of the Labor Wedge}

Following most of the literature, we define the labor wedge as the ratio of the marginal rate of substitution between leisure and consumption (MRS) and the marginal product of labor (MP). Figure 1 depicts the behavior of these two determinants of the labor wedge. The shaded vertical areas correspond to the official recession periods according to NBER. The picture forces one to conclude that most of the volatility of the labor wedge comes from variations in the marginal rate of substitution, rather than the marginal product. Though we estimate the elasticity of the utility function to be high, this result is true for most values of the elasticity used in the macro literature. ${ }^{9}$

In the context of our model, the labor wedge has a new interpretation. The MRS represents the reservation value (outside option) of workers when bargaining over the wage, which implies that the difference between the MP and the MRS represents the instantaneous welfare gain of a new match. ${ }^{10}$ It is clear from Figure 1 that the bargaining set narrows in good times and widens significantly in recessions. Thus, in bad times the labor wedge widens, reflecting an increase in the value of new matches and vice versa.

\footnotetext{
${ }^{9}$ If we fix the elasticity at lower values and re-estimate the model, the results are very similar.

${ }^{10}$ The behavior of the instantaneous gain is very similar to that of the lifetime gain.
} 


\subsection{Behavior of the Underlying Shocks}

Given the estimated parameter values, we can compute the underlying shocks using the Kalman filter. Figure 2 describes the behavior of the recovered shocks over the whole forty-five year period. Note that TFP and investment shocks are random walks with drifts, while the rest of the processes are stationary.

We find that total factor productivity slows down at the beginning of each recession. The investment specific technology tends to increase in recessions and has a negligible effect on output and the labor market variables. This supports the main finding of CKM, that the investment wedge plays only a tertiary role in U.S. business cycles. The government shock as well as the investment shock, only affects consumption and investment. Because we are primarily interested in the behavior of output, hours, unemployment and vacancies, for the rest of the exposition we abstract from the behavior of investment and government shocks. Instead we focus on technological shocks and shocks that make up the labor wedge.

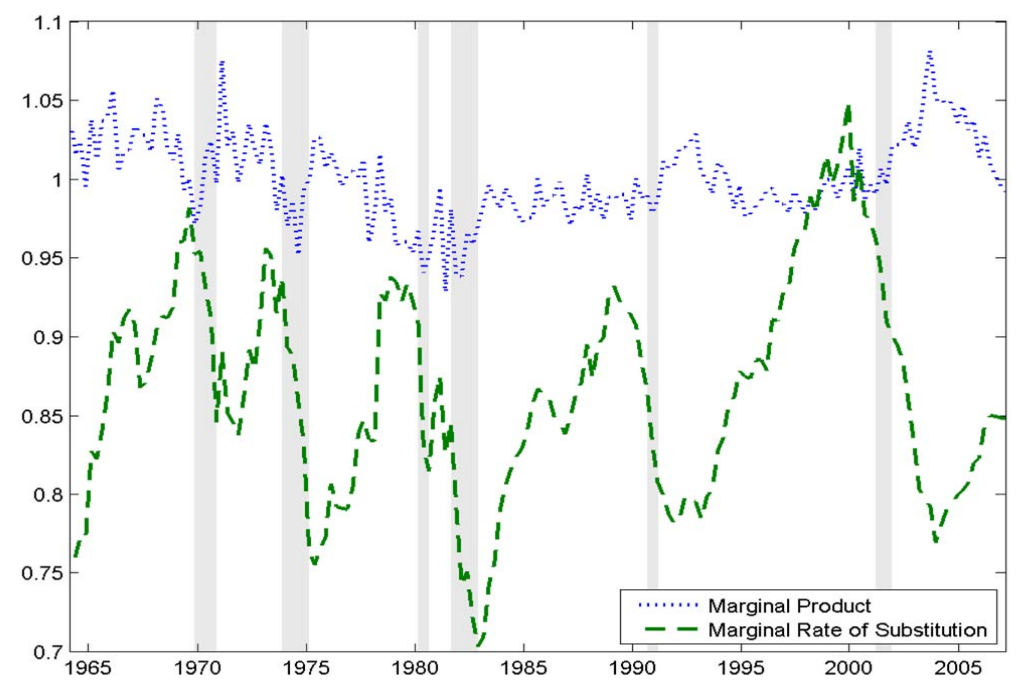

Figure 1: The Labor Wedge

Figure 2 demonstrates that the separation rate tends to be high at the beginning of each recession. ${ }^{11}$ The wave of separations typically starts earlier

\footnotetext{
${ }^{11}$ As a consistency check note, these spikes in the separation rate typically coincide with
} 

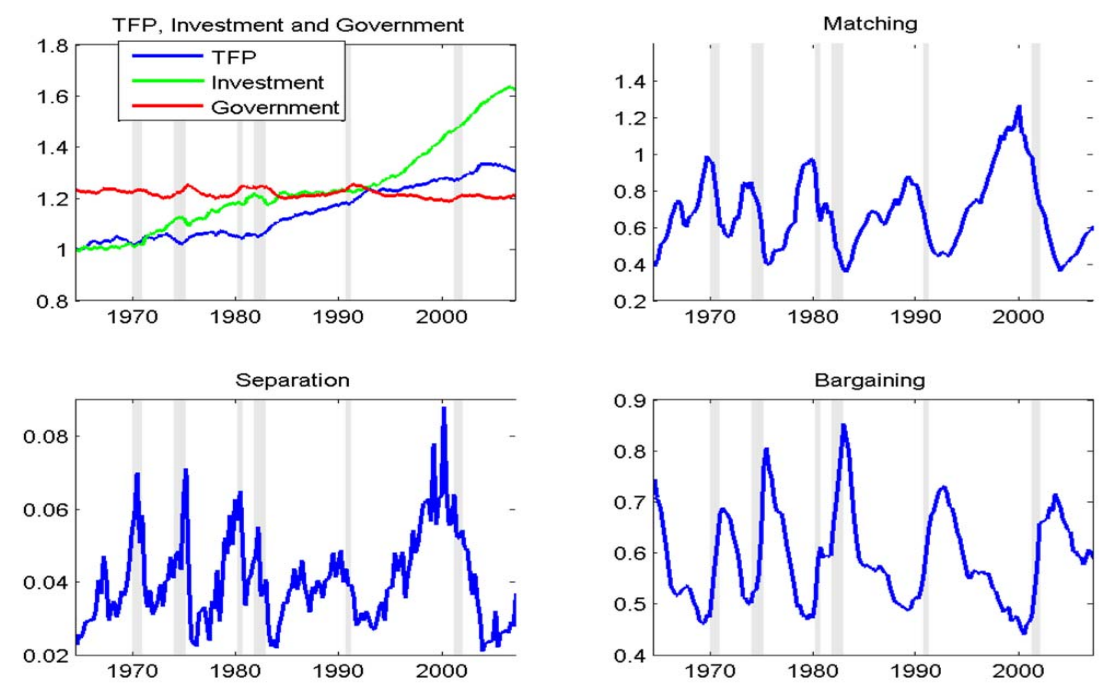

Figure 2: The six shocks

than the recession itself and dies out quickly — within a year after the start of a recession.

Notice as well the large decreases in the matching efficiency at later stages of recessions which lead to declines in the number of new matches and, hence, cause the amounts of hours worked to fall. While the outside option of the worker tends to decrease in recessions because of a decrease in their marginal disutility of work, an increase in the bargaining power tends to leave wages largely unchanged. Thus, our finding that bargaining power of workers increases significantly during recessions is consistent with a view of wage stickiness as a major source of inefficiency in the labor market.

Let us now take a closer look at the timing of shocks. From Figure 2 it is clear that declines in TFP slightly precede increases in the separation rate. An increase in the separation rate is typically followed by an increase in the bargaining power of workers which precedes or coincides with a decrease in the matching shock (see also cross-correlations in Appendix D). This implies that shocks to the separation rate are important at early stages of recessions, and bargaining and matching shocks come into play later.

spikes observed in Shimer's data. 


\subsection{Decomposition of the Labor Wedge}

To measure the contribution of each shock to a given variable, we shut down the innovations to it and simulate the model. We obtain paths of output, hours, unemployment and vacancies, which would have taken place, if only this distortion were absent. This allows us to compare the actual paths of variables to their hypothetical paths in a world where one of the imperfections is absent.

Shutting down innovations to each one of the labor market shocks reveals a striking picture. Figure 3 shows that absence of separation and bargaining shocks leaves the labor wedge essentially unchanged, while the absence of shocks to matching efficiency produces an essentially constant labor wedge. Thus, most of the fluctuations in the labor wedge are explained by matching shocks alone.

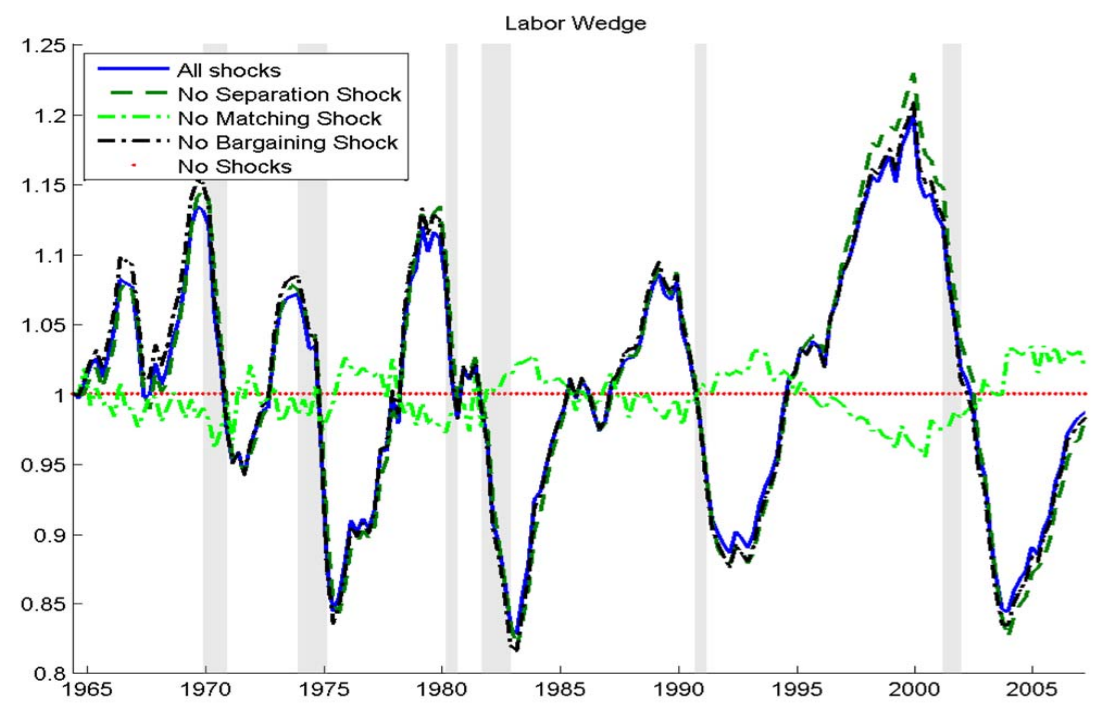

Figure 3: The decomposition of the labor wedge

Remember that when the Hosios condition holds on average, changes in the bargaining power do not affect the labor wedge. Our calibration of $\theta$ of 0.7 as suggested by Shimer and our estimate of the steady-state value of the bargaining power of 0.56 are not that far. ${ }^{12}$ Hence, our result that the

\footnotetext{
${ }^{12}$ The effects of the difference between $\theta$ and $\phi_{\text {ss }}$ are second order, so a difference of $20 \%$ would account for $0.2^{2} / 2=2 \%$ of variations in the labor wedge.
} 


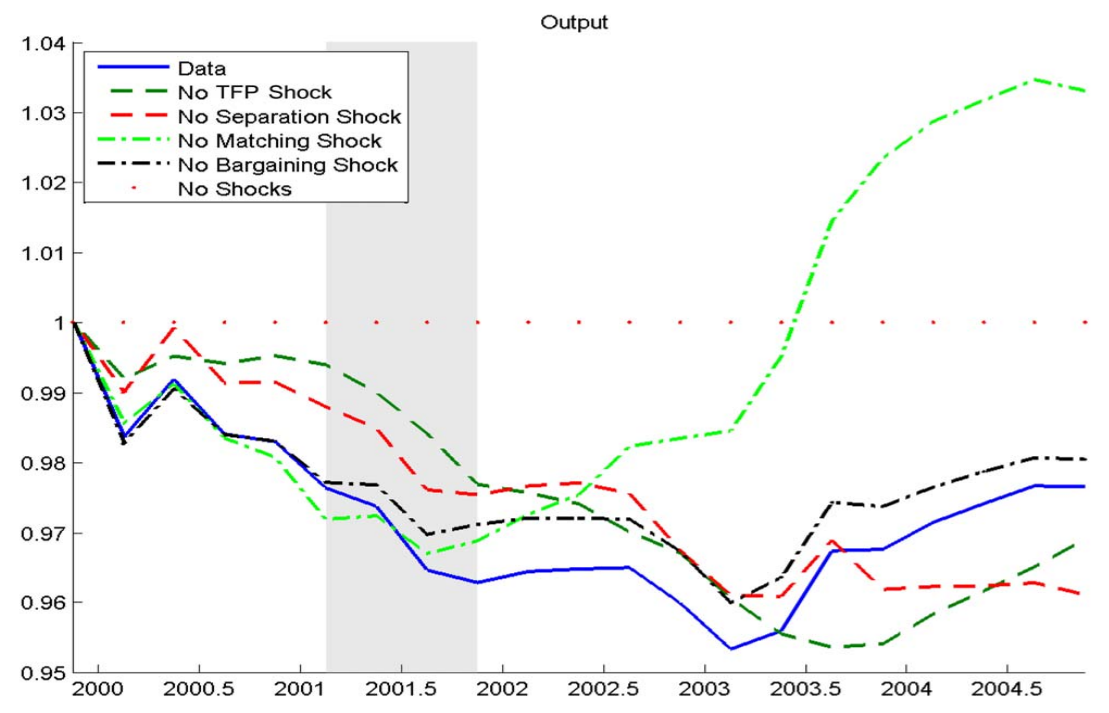

Figure 4: Output with all but one shock

bargaining shock has little or no effect on the labor wedge is not all that surprising.

\subsection{Decomposition of Output and Unemployment}

To analyze in detail the effects of each shock on output and unemployment and the timing patterns, we focus on the 2001 recession episode, which is the last recession in our sample. We use this recession to illustrate our results as it is easier to see the results in a more detailed graph than it is to see them in a graph containing the whole period. At the end of the section, we show that the results hold for all recession periods in the sample.

As in the previous subsection, we compare the actual path of GDP with paths it would have taken if we eliminate effects of just one of the shocks.

Although only matching shocks matter for the labor wedge, the impact on output is not so clear-cut. Figure 4 illustrates the effects of shocks to TFP, the separation rate, the bargaining power of workers and the matching efficiency on output.

The vertical axis measures percentage deviations from the path that output would have followed, if all the shocks were constant (the random walks would preserve their drifts, but innovations are shut down). The solid line 
depicts the actual path of output in the data. The rest of the lines depict the paths of output if we shut down innovations to just one of the shocks, eliminating its effect on the economy.

Figure 4 shows that if there were no change in total factor productivity, the recession probably would not have started. If there were no separation shocks at the early stage of the recession, output would have fallen by half as much. The bargaining shocks added to the depth of the recession, while shocks to matching efficiency are key to understanding the slow recovery: in the absence of the adverse matching shocks, the economy would have fully recovered by summer of 2003.

Thus, Figure 4 demonstrates that although matching shocks explain most of the dynamics of the labor wedge, they can only account for a fraction of output dynamics. While shocks to TFP and the separation rate start recessions by accounting for the initial slowdown in output, the role of bargaining and matching shocks is to deepen the recession and delay the recovery.

Figure 5 depicts a similar decomposition of unemployment. It follows from Figure 5 that separation shocks are responsible for the initial increase in unemployment. Increases in the bargaining power of workers start playing a role only once the economy is already in a recession, reinforcing this initial increase in unemployment. Declines in matching efficiency leave unemployment at a high level for a longer period of time after the official recession has already ended, thus accounting for the so-called jobless recovery.

Therefore, after some firms in the economy have become less productive, the role of the separation shock is to create the initial pool of unemployed people. As the number of unemployed goes up, the reservation value of workers goes down significantly - they are willing to work at a lower wage. The sluggish response of wages drives up the bargaining power of the workers, while the firm is now in a worsened position. As a result firms start posting less vacancies, and there are more and more unemployed in the market. Consistent with this explanation, the sharp increase in the bargaining power of workers accounts for the bulk of changes in unemployment and vacancies in the second phase of the recession.

As the number of workers seeking jobs is high and the number of vacancies is low, the matching efficiency goes down, thus causing output to fall deeper and the recession to last longer. Figure 5 confirms that if there were no decline in matching efficiency, the recovery from the recession would have been much faster. Hence, the so-called "jobless recovery" is due mainly to matching shocks. We attribute this to some form of congestion, which still 


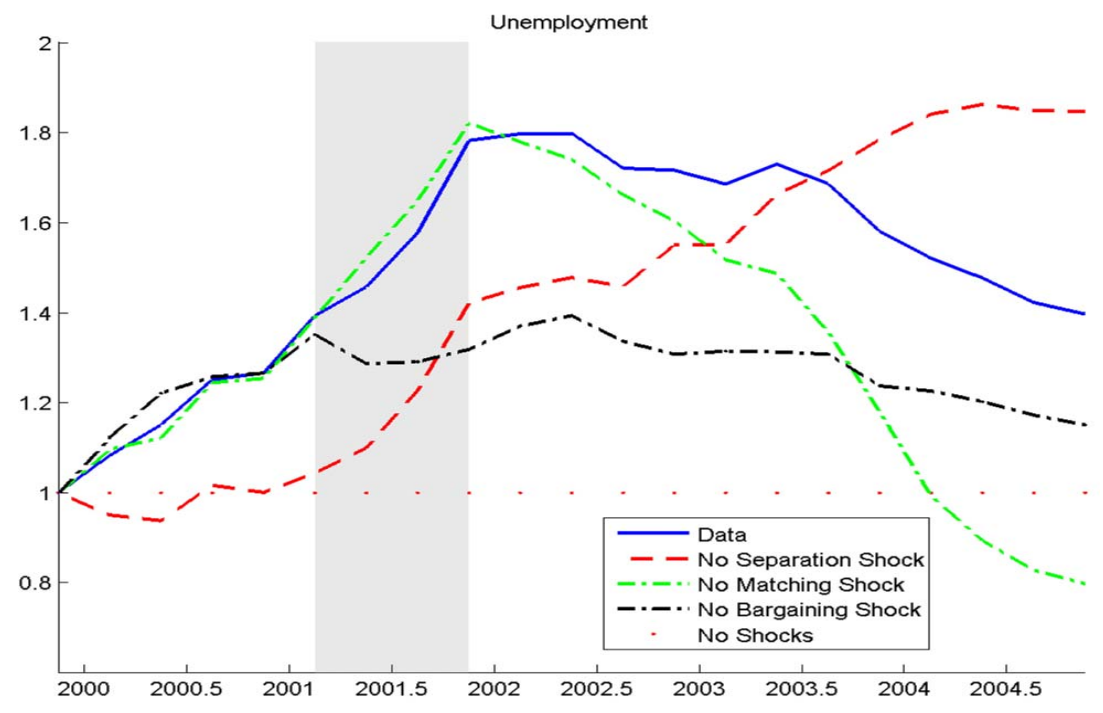

Figure 5: Unemployment with all but one shock

requires an explanation. It can also be some form of disorganization, when the least efficient and more specialized workers become desperate to find a job and wait until better times, consistent with the idea of rest unemployment.

\subsection{Decompositions: Summary}

Note that the statements made regarding the last recession hold more generally over the period of interest. A similar decomposition of the previous four recession episodes shows that the emphasized pattern holds more generally: separations create the initial pool of unemployed, and adverse matching shocks slow down the recovery.

To summarize contributions of each shock to each variable of interest, we set all the other shocks to their steady-state values and simulate the model. We obtain paths of output, hours, unemployment and vacancies, which would have taken place if all the other distortions except one were absent. Table 4 reports fractions of standard deviations of output, hours, unemployment and vacancies, that can be explained by each one of the shocks.

The contribution of the "labor wedge" is measured by hitting the economy by three shocks: separation, bargaining and matching - at the same time. Earlier we have shown that in our model the "labor wedge" is an 


\begin{tabular}{|l|c|c|c||c|c|c|}
\hline Shock & TFP & Invest-t & Labor & Separation & Matching & Bargaining \\
\hline Output & 0.67 & 0.09 & 0.71 & 0.31 & 0.61 & 0.14 \\
\cline { 2 - 7 } Hours & 0.07 & 0.12 & 1.03 & 0.41 & 1.10 & 0.25 \\
\cline { 2 - 7 } Unemp-t & 0.06 & 0.04 & 1.02 & 1.08 & 1.26 & 0.67 \\
\cline { 2 - 7 } Vacancies & 0.06 & 0.04 & 1.04 & 0.85 & 0.95 & 1.23 \\
\hline
\end{tabular}

Table 4: Ratios of standard deviations explained by each shock over the whole period

exact combination of just these three shocks (see equation (28)). We thus provide an exact decomposition of the labor wedge into job destruction and job creation shocks.

These results address the debate between Fujita and Ramey (2007) and Shimer $(2005 b)$ on whether job destruction or job creation is more important for fluctuations in unemployment and output. We find that although shocks to job creation are more important for the behavior of output and unemployment, shocks to job destruction cannot be ignored. Changes in the separation rate account for a significant fraction of fluctuations and explain the initial increase in unemployment and decrease in output. Essentially, these shocks start the recession. Thus, even though their contribution is relatively small, without job destruction shocks recessions might not have happened in the first place.

\subsection{Wages and Shimer's Puzzle}

In an influential paper, Shimer (2005a) shows that a standard MortensenPissarides-type model, when hit by productivity shocks of plausible magnitude, predicts wages to be more volatile than in the data, while generating relatively small variations in unemployment and vacancies. This is known as Shimer's puzzle.

Our model fits the volatility of unemployment and vacancies by construction. Figure 6 depicts the behavior of wages predicted by the model and compares it to data (adjusted for the stochastic trend). The model predicts wages as volatile as in the data, and the correlation between the two is high (0.56). It is important to consider that we are not using observed wages in the estimation procedure. The ability of the model to generate a wage series that close to the observed one is remarkable.

The predicted wage level splits the instantaneous value of the match be- 


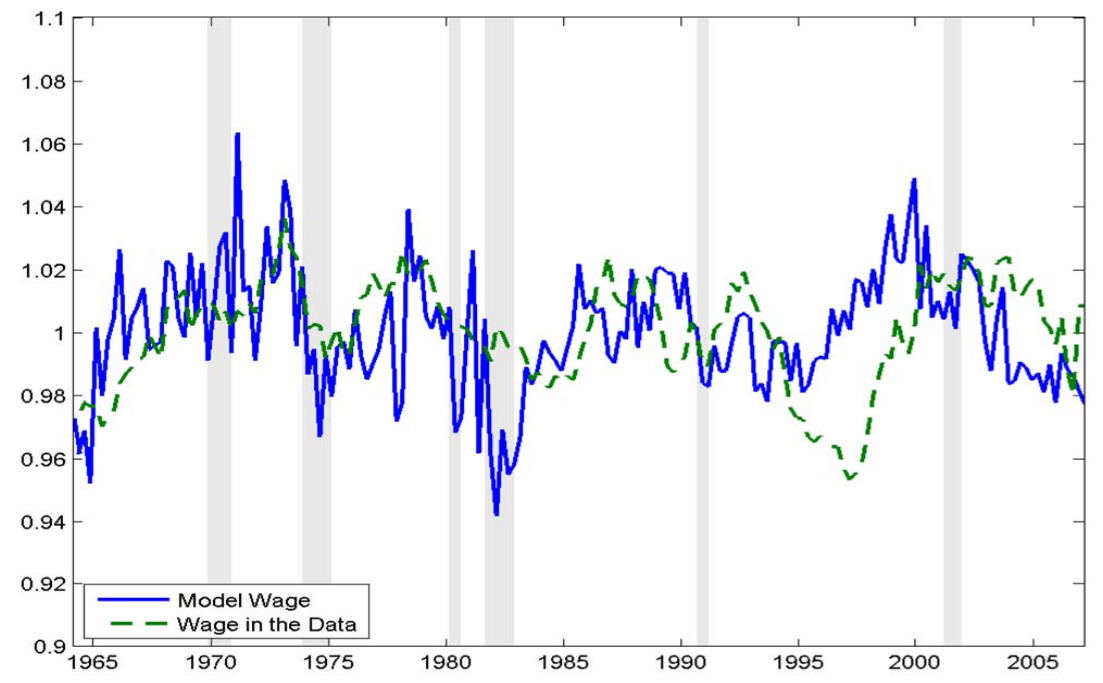

Figure 6: Wages: model versus data

tween the worker and the firm in the proportion of their bargaining weights, as illustrated by Figure 7 .

Figure 7 demonstrates that while the reservation value of workers falls in recessions, wages stay fairly constant, thus indicating that the bargaining power of workers increases in recessions. This result supports wage stickiness as a mechanism behind the large changes in the bargaining power of the workers. However, unlike previous models of Hall (2005a) and Farmer and Hollenhorst (2006), where increases in the bargaining power in recessions were a result of declines in the marginal product combined with wage stickiness, in our model they are a consequence of declines in the reservation value (MRS) together with wage stickiness.

Thus, allowing for changes in the marginal rate of substitution between consumption and leisure and, consequently, for changes in the reservation value of workers, our model both matches the volatile behavior of unemployment and vacancies, and predicts an absence of significant fluctuations in wages, just as in the data. Hence, by allowing for variations in the outside option of workers our model provides a mechanism, which can solve Shimer's puzzle.

Why do we get these large swings in the marginal rate of substitution, in the matching efficiency and in the bargaining power? We think that this 
should be a general result in models where agents decide on the margin. More precisely, we argue that models, where workers and firms equalize benefits and costs of searching for a job and opening a vacancy, would predict sizable changes both in shocks and incentives.

First, notice that when workers choose whether to search for a job (equation (14)), they equate the cost of searching for a job - which is equal to the MRS in our model - with the potential benefits of forming a match times the probability of finding a job. The benefits are equal to the present discounted value of the wages minus the cost of working, which is also equal to MRS:

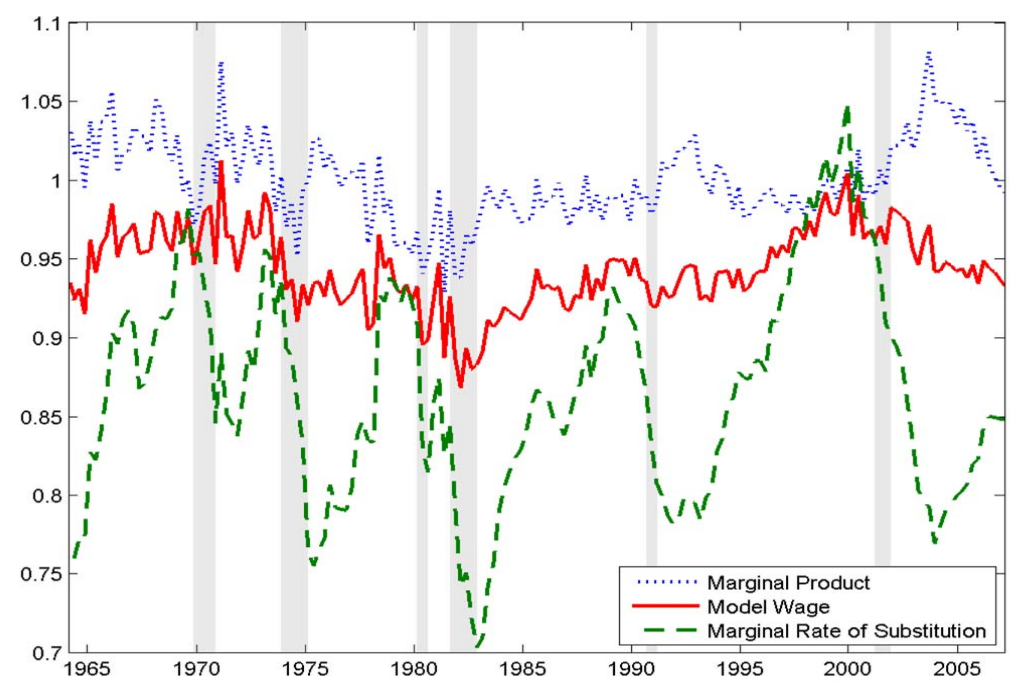

Figure 7: Variations in the bargaining set

$$
M R S_{t}=\phi_{t} \Gamma_{t} \frac{M_{t}}{U_{t}}=P V\left(W_{t}-M R S_{t}\right) \frac{M_{t}}{U_{t}}
$$

Given that in the data the job finding probability $\frac{M_{t}}{U_{t}}$ declines significantly in recessions (documented by Shimer $(2005 a)$ ) and the wage is fairly constant, equation (30) implies that the MRS has to fall by a fair amount. In the model the large swings in the MRS are due to the estimated elasticity of the utility function of 3.54 - a significantly bigger number than 0.5, typically assumed in the RBC literature. This result leads us to obtain a much more volatile series for the labor wedge, which, nonetheless, matches the behavior 
of previous estimates very well. For a comparison of our labor wedge with the labor wedge of CKM, see Appendix D.

Secondly, notice that when firms choose whether to open a new vacancy, they also equate the competitive salary they pay to a head-hunter with the potential benefits of forming a match times the probability of finding a worker to fill the vacancy. The benefits are equal to the present discounted value of the marginal product minus the wage that they pay to the worker:

$$
M R S_{t}=\left(1-\phi_{t}\right) \Gamma_{t} \frac{M_{t}}{V_{t}}=P V\left(M P_{t}-W_{t}\right) B_{t}\left(\frac{U_{t}}{V_{t}}\right)^{\theta}
$$

Given that we have already established the significant decreases in the MRS in recessions, and taking into account the fact that in the data unemployment increases, while the number of vacancies falls and both the wage and the marginal product are not very volatile, equation (31) implies that the matching efficiency has to fall significantly in recessions.

Combining equations (30) and (31) one can find that the bargaining power of the workers is directly pinned down by the market tightness:

$$
\frac{1-\phi_{t}}{\phi_{t}}=\frac{V_{t}}{U_{t}}
$$

Thus, when unemployment increases and there are fewer vacancies, the bargaining power of workers has to increase by a comparable amount. Variations in the separation rate that we estimate are a residual of the labor accumulation equation in the productive sector.

To summarize, for a model, where both households and firms decide on the margin how much time to spend searching for each other, to match aggregate data, one needs to generate large changes in both the marginal rate of substitution between consumption and leisure and the bargaining power of workers. Procyclical reservation values, along with countercyclical bargaining power of workers, help match the volatile behavior of unemployment and vacancies and predict absence of significant fluctuations in wages, just as in the data. This mechanism provides a solution to Shimer's puzzle.

\section{Conclusion}

Motivated by the fact that variations in the labor wedge account for a large fraction of business cycle fluctuations, we look at the labor wedge through 
the lens of a search and matching model. Using a model that features timevarying search and matching frictions in the spirit of Mortensen and Pissarides (1994), Shimer (2005a) and Hall (2005a) we decompose the labor wedge into three broad classes of frictions captured by separation, bargaining and matching shocks. Using a business cycle accounting methodology similar to that of Chari, Kehoe and McGrattan (2007), we identify the sources of variations in the labor wedge and assess the importance of job destruction (separation) and job creation (bargaining and matching) frictions for business cycles.

We find that imperfections in the job destruction and bargaining processes are not helpful in explaining the labor wedge which is mainly driven by matching shocks. This implies that theories emphasizing wage stickiness and endogenous job destruction are not very useful for explaining the behavior of the labor wedge. Instead, according to our results, more attention should be devoted to studying frictions equivalent to the matching shock in our model, for example, frictions that lead to cyclical variations in job creation costs, search effort, or coordination problems. More specifically, one potential microfoundation for the matching shock in our model is proposed by Lester (forthcoming), who shows that when firms have the ability to post multiple vacancies then the efficiency of the matching process depends on the distribution of vacancies among firms, increasing in concentration of vacancies.

Although only matching shocks affect the labor wedge, both frictions in job creation and job destruction play an important role in output and unemployment fluctuations. We find that job destruction and job creation shocks play a role at different points in time. In a recession, separation shocks account for the initial increase in unemployment, bargaining shocks help amplify the increase in unemployment, while matching shocks are responsible for the slow recovery.

Finally, our results also provide a potential solution to Shimer's puzzle. We find that introducing variations in the reservation value of workers is a feature worth exploring in search and matching models in order to match the observed volatility of unemployment, vacancies and wages.

\section{References}

Andolfatto, David. 1996. "Business Cycles and Labor-Market Search." American Economic Review, 86(1): 112-32. 
An, Sungbae, and Frank Schorfheide. 2007. "Bayesian Analysis of DSGE Models." Econometric Reviews, 26(2-4): 113-172.

Blanchard, Oliver Jean, and Peter Diamond. 1989. "The Beveridge Curve." Brookings Papers on Economic Activity, 20(1989-1): 1-76.

Canova, Fabio. 1998. "Detrending and Business Cycle Facts." Journal of Monetary Economics, 41(3): 475-512.

Chari, V. V., Patrick J. Kehoe, and Ellen R. McGrattan. 2007. "Business Cycle Accounting." Econometrica, 75(3): 781-836.

Cogley, Timothy, and James M. Nason. 1995. "Effects of the HodrickPrescott Filter on Trend and Difference Stationary Time Series: Implications for Business Cycle Research." Journal of Economic Dynamics and Control, 19(1-2): 253-278.

Cole, Harold L., and Lee E. Ohanian. 2002. "The U.S. and U.K. Great Depressions Through the Lens of Neoclassical Growth Theory." American Economic Review, 92: 28 - 32 [826].

Farmer, Roger E. A., and Andrew Hollenhorst. 2006. "Shooting the Auctioneer." NBER Working Paper, 12584.

Fernandez-Villaverde, Jesus, and Juan F. Rubio-Ramirez. 2007. "Estimating Macroeconomic Models: A Likelihood Approach." Review of Economic Studies, 74(4): 1059-1087.

Fujita, Shigeru, and Garey Ramey. 2007. "Reassessing the Shimer Facts." Federal Reserve Bank of Philadelphia, Working Paper, 07-2.

Gertler, Mark, Luca Sala, and Antonella Trigari. 2008. "An Estimated Monetary DSGE Model with Unemployment and Staggered Nominal Wage Bargaining." Journal of Money, Credit and Banking, 40(8): 17131764 .

Hagedorn, Marcus, and Iourii Manovskii. 2008. "The Cyclical Behavior of Equilibrium Unemployment and Vacancies Revisited." American Economic Review, 98(4): 1692-1706.

Hall, Robert E. 2005a. "Employment Fluctuations with Equilibrium Wage Stickiness." American Economic Review, 95(1): 50-65. 
Hall, Robert E. 2005b. "The Labor Market and Macro Volatility: A Nonstationary General-Equilibrium Analysis." NBER Working Paper, 11684 .

Hansen, Gary D. 1986. "Growth and Fluctuations." University of California at Santa Barbara, Unpublished.

Hosios, Arthur J. 1990. "On the Efficiency of Matching and Related Models of Search and Unemployment." Review of Economic Studies, 57(2): 279-98.

King, Robert G., Charles I. Plosser, and Sergio T. Rebelo. 1988. "Production, Growth and Business Cycles : I. The Basic Neoclassical Model." Journal of Monetary Economics, 21(2-3): 195-232.

Lester, Benjamin. forthcoming. "Directed Search with Multi-Vacancy Firms." Journal of Economic Theory.

Lubik, Thomas A. 2009. "Estimating a Search and Matching Model of the Aggregate Labor Market." Economic Quarterly, 95(2): 101-120.

Merz, Monika. 1995. "Search in the Labor Market and the Real Business Cycle." Journal of Monetary Economics, 36(2): 269-300.

Mortensen, Dale, and Eva Nagypal. 2007. "More on Unemployment and Vacancy Fluctuations." Review of Economic Dynamics, 10(3): 327-347.

Mortensen, Dale T, and Christopher A Pissarides. 1994. "Job Creation and Job Destruction in the Theory of Unemployment." Review of Economic Studies, 61(3): 397-415.

Shimer, Robert. 2005a. "The Cyclical Behavior of Equilibrium Unemployment and Vacancies." American Economic Review, 95(1): 25-49.

Shimer, Robert. 2005b. "The Cyclicality of Hires, Separations, and Job-tojob Transitions." Federal Reserve Bank of St. Louis Review, 87(4): 493508 .

Shimer, Robert. 2010. Labor Markets and Business Cycles. Princeton University Press. 


\section{A Appendix.}

\section{A.1 Appendix A}

In the following subsection we show the solution to the same model as in the main body of the paper, but when solved as a social planner's problem. The decentralized version of the model has a missing equilibrium condition that is typically replaced with a Nash bargaining condition to fix the real wage. We take advantage of this missing condition, and by comparing the social planner's solution with the decentralized version of the model, we construct a time varying bargaining shock, which implicitly determines the wage rate.

\section{A.1.1 The Social Planner's Problem}

To compare competitive allocations with an efficient one we solve the social planning problem. The social planner maximizes the discounted present value of the utility function:

$$
\max _{\left\{C_{t}, L_{t}, V_{t}, U_{t}, K_{t+1}\right\}} E_{t} \sum_{t=0}^{\infty} \beta^{t} U\left(C_{t}, L_{t}, V_{t}, U_{t}\right)
$$

subject to

$$
\begin{gathered}
C_{t}+\frac{1}{T_{t}}\left(K_{t+1}-\left(1-\delta_{K}\right) K_{t}\right)+G_{t} \leq A_{t} F\left(K_{t}, L_{t}\right) \\
L_{t}=\left(1-\delta_{L}\right) L_{t-1}+M_{t}
\end{gathered}
$$

The optimality conditions of the planner are given by:

$$
\begin{gathered}
\frac{1}{T_{t}}=\beta E_{t} \frac{U_{C_{t+1}}^{\prime}}{U_{C_{t}}^{\prime}}\left(A_{t+1} F_{K_{t+1}}^{\prime}\left(K_{t}, L_{t}\right)+\frac{1}{T_{t}}\left(1-\delta_{K}\right)\right) \\
A_{t} F_{L_{t}}^{\prime}\left(K_{t}, L_{t}\right)+\frac{U_{L_{t}}^{\prime}}{U_{C_{t}}^{\prime}}=\Gamma_{t}-\beta E_{t}\left(\frac{U_{C_{t+1}}^{\prime}}{U_{C_{t}}^{\prime}} \Gamma_{t+1}\left(1-\delta_{L t}\right)\right) \\
-\frac{U_{V_{t}}^{\prime}}{U_{C_{t}}^{\prime}}=\Gamma_{t} \frac{\partial M_{t}}{\partial V_{t}} \\
-\frac{U_{U_{t}}^{\prime}}{U_{C_{t}}^{\prime}}=\Gamma_{t} \frac{\partial M_{t}}{\partial U_{t}}
\end{gathered}
$$


Together with equations (7)-(8) they describe the allocations a social planner would choose. $\Gamma_{t}$ is the Lagrange multiplier associated with the labor accumulation constraint. Given that $T_{t}, A_{t}, \delta_{L t}, G_{t}$ and $B_{t}$ are exogenous, we have a system of eight equations and eight unknowns $\left\{K_{t+1}, L_{t}, C_{t}, M_{t}, Y_{t}, V_{t}, U_{t}, \Gamma_{t}\right\}$.

\section{A.1.2 Constructing a Time Varying Bargaining Shock}

By comparing the social planner's optimality conditions with those of the decentralized problem, we can find the necessary assumptions to make the decentralized problem efficient.

By putting equations (12) and (13) together we get that $-\frac{U_{V_{t}}^{\prime}}{U_{C_{t}}^{\prime}}=\eta_{t} \frac{M_{t}}{V_{t}}$, and if we compare this expression with equation (38), and equation (14) with equation (39), we need

$$
\begin{aligned}
\eta_{t} \frac{M_{t}}{V_{t}} & =\Gamma_{t} \frac{\partial M_{t}}{\partial V_{t}} \\
\mu_{t} \frac{M_{t}}{U_{t}} & =\Gamma_{t} \frac{\partial M_{t}}{\partial U_{t}}
\end{aligned}
$$

so that the optimality conditions on vacancies and unemployment are the same in the decentralized and planner's problem. Furthermore, if we assume that the matching function has constant returns to scale

$$
\frac{\partial M\left(U_{t}, V_{t}\right)}{\partial U_{t}} U_{t}+\frac{\partial M\left(U_{t}, V_{t}\right)}{\partial V_{t}} V_{t}=M\left(U_{t}, V_{t}\right)
$$

then $\Gamma_{t}=\mu_{t}+\eta_{t}$ and the decentralized outcome is Pareto-optimal. Hence, the Hosios condition for efficiency is given by:

$$
\begin{aligned}
\eta_{t} & =\Gamma_{t} \frac{\partial M_{t}}{\partial V_{t}} \frac{V_{t}}{M_{t}} \\
\mu_{t} & =\Gamma_{t} \frac{\partial M_{t}}{\partial U_{t}} \frac{U_{t}}{M_{t}}
\end{aligned}
$$

As an illustration, assume $\frac{\partial M_{t}}{\partial U_{t}} \frac{U_{t}}{M_{t}}=\theta$ and $\frac{\partial M_{t}}{\partial V_{t}} \frac{V t}{M_{t}}=(1-\theta)$, which together with conditions (43) and (44) give

$$
\eta_{t}=(1-\theta) \Gamma_{t}
$$

and 


$$
\mu_{t}=\theta \Gamma_{t}
$$

Notice that if we replace equations (45) and (46) in equations (10) and (11) and sum them up, we get equation (37), hence the optimality conditions for labor in the decentralized version become equal to the optimality condition for labor in the planners problem.

Furthermore, if we divide equation (10) by equation (11) and use equations (45) and (46) we get

$$
\frac{w_{t}+\frac{U_{L_{t}}^{\prime}}{U_{C_{t}}^{\prime}}}{A_{t} F_{L_{t}}^{\prime}\left(K_{t}, L_{t}\right)-w_{t}}=\frac{\mu_{t}-\beta E_{t}\left(\frac{U_{C_{t+1}}^{\prime}}{U_{C_{t}}^{\prime}} \mu_{t+1}\left(1-\delta_{L t+1}\right)\right)}{\eta_{t}-\beta E_{t}\left(\frac{U_{C_{t+1}}^{\prime}}{U_{C_{t}}^{\prime}} \eta_{t+1}\left(1-\delta_{L t+1}\right)\right)}=\frac{\theta}{1-\theta}
$$

Given that $w_{t}$ is the wage earned by the worker, and $-\frac{U_{L_{t}}^{\prime}}{U_{C_{t}}^{\prime}}$ is his reservation utility, the term $w_{t}+\frac{U_{L_{t}}^{\prime}}{U_{C_{t}}^{\prime}}$ represents the instantaneous benefit from the match earned by the worker. Since the bargaining power of the worker is constant and equal to $\theta$, the optimal wage rate satisfies

$$
\left(w_{t}+\frac{U_{L_{t}}^{\prime}}{U_{C_{t}}^{\prime}}\right)=\theta\left(A_{t} F_{L_{t}}^{\prime}\left(K_{t}, L_{t}\right)+\frac{U_{L_{t}}^{\prime}}{U_{C_{t}}^{\prime}}\right)
$$

where $A_{t} F_{L_{t}}^{\prime}\left(K_{t}, L_{t}\right)+\frac{U_{L_{t}}^{\prime}}{U_{C_{t}}^{\prime}}$ is the difference between the marginal product of labor and the marginal disutility of labor. This term represents the instantaneous marginal value of the match, and a fraction $\theta$ goes to the worker.

To introduce the time varying bargaining shock we build on this result, re-parameterize and substitute $\theta$ by $\phi_{t}$. $\phi_{t}$ is time varying and follows an exogenous autoregressive process. Notice that replacing $\theta$ by $\phi_{t}$ implies that allocations are suboptimal whenever $\phi_{t} \neq \theta$.

Equations (45) and (46) are replaced by

$$
\begin{gathered}
\eta_{t}=\left(1-\phi_{t}\right) \Gamma_{t} \\
\mu_{t}=\phi_{t} \Gamma_{t}
\end{gathered}
$$

Once again if we substitute equations (49) and (50) in (10) and (11) we get equation (37) so it is still true that the optimality conditions for labor of the 
decentralized version imply the optimality condition for labor of the planner's problem. Dividing equation (10) by equation (11) and using equations (49) and (50) we get

$$
\frac{w_{t}+\frac{U_{L_{t}}^{\prime}}{U_{C_{t}}^{\prime}}}{A_{t} F_{L_{t}}^{\prime}\left(K_{t}, L_{t}\right)-w_{t}}=\frac{\phi_{t} \Gamma_{t}-\beta E_{t}\left(\frac{U_{C_{t+1}}^{\prime}}{U_{C_{t}}^{\prime}} \phi_{t+1} \Gamma_{t+1}\left(1-\delta_{L t+1}\right)\right)}{\left(1-\phi_{t}\right) \Gamma_{t}-\beta E_{t}\left(\frac{U_{C_{t+1}}^{\prime}}{U_{C_{t}}^{\prime}}\left(1-\phi_{t+1}\right) \Gamma_{t+1}\left(1-\delta_{L t+1}\right)\right)}
$$

hence, the optimal wage rate satisfies

$$
\left(w_{t}+\frac{U_{L_{t}}^{\prime}}{U_{C_{t}}^{\prime}}\right)=\frac{\phi_{t}-\beta E_{t}\left(\frac{U_{C_{t+1}}^{\prime}}{U_{C_{t}}^{\prime}} \phi_{t+1} \Psi_{t+1}\right)}{1-\beta E_{t}\left(\frac{U_{C_{t+1}}^{\prime}}{U_{C_{t}}^{\prime}} \Psi_{t+1}\right)}\left(A_{t} F_{L_{t}}^{\prime}\left(K_{t}, L_{t}\right)+\frac{U_{L_{t}}^{\prime}}{U_{C_{t}}^{\prime}}\right)
$$

where $\Psi_{t+1}=\frac{\Gamma_{t+1}}{\Gamma_{t}}\left(1-\delta_{L t+1}\right)$ and can be interpreted as a stochastic discount factor for labor.

\section{A.1.3 Identification}

In this section we show how given data on allocations: output, investment, consumption, employment, vacancies and unemployment one can solve for the shocks. Let us first rewrite the equations of the model given the parametric assumptions and functional forms used in the paper:

$$
\begin{gathered}
Y_{t}=A_{t} K_{t}^{\alpha} L_{t}^{1-\alpha} \\
X_{t}=K_{t+1}-\left(1-\delta_{K}\right) K_{t} \\
C_{t}+\frac{X_{t}}{T_{t}}+G_{t}=Y_{t} \\
L_{t}=\left(1-\delta_{L t}\right) L_{t-1}+B_{t} U_{t}^{\theta} V_{t}^{1-\theta} \\
\frac{1}{T_{t}}=\beta E_{t} \frac{C_{t}}{C_{t+1}}\left(\alpha \frac{Y_{t+1}}{K_{t+1}}+\frac{\left(1-\delta_{K}\right)}{T_{t+1}}\right)
\end{gathered}
$$




$$
\begin{gathered}
\mu_{t}=w_{t}-C_{t} \chi\left(L_{t}+U_{t}+V_{t}\right)^{\gamma}+\beta E_{t} \frac{C_{t}}{C_{t+1}} \mu_{t+1}\left(1-\delta_{L t+1}\right) \\
\eta_{t}=(1-\alpha) \frac{Y_{t}}{L_{t}}-w_{t}+\beta E_{t} \frac{C_{t}}{C_{t+1}} \eta_{t+1}\left(1-\delta_{L t+1}\right) \\
C_{t} \chi\left(L_{t}+U_{t}+V_{t}\right)^{\gamma}=\eta_{t} B_{t}\left(\frac{U_{t}}{V_{t}}\right)^{\theta} \\
C_{t} \chi\left(L_{t}+U_{t}+V_{t}\right)^{\gamma}=\mu_{t} B_{t}\left(\frac{V_{t}}{U_{t}}\right)^{1-\theta} \\
\frac{\eta_{t}}{\mu_{t}}=\frac{1-\phi_{t}}{\phi_{t}}
\end{gathered}
$$

Now we shall describe a mechanism to recover the shocks given parameters and functional forms. Given data on consumption $C_{t}$ (or government spending $G_{t}$ ), output $Y_{t}$, investment $X_{t}$, employment $L_{t}+V_{t}$, number of vacancies $V_{t}$ and the unemployment rate $\frac{U_{t}}{L_{t}+V_{t}+U_{t}}$, one can uniquely recover the time path for the variables of interest $L_{t}, V_{t}, U_{t}$. Then equation (54) uniquely pins down the path for capital given the initial level $K_{0}$, equation (53) pins down the efficiency shock $A_{t}$, equation (55) pins down consumption or government spending, equation (57) can be solved forward to obtain the path for the investment shock as in CKM.

From equations (60) and (61) it follows that $\eta_{t} U_{t}=\mu_{t} V_{t}$. Then summing up equations (58) and (59) one obtains:

$$
\begin{array}{r}
-C_{t} \chi\left(L_{t}+U_{t}+V_{t}\right)^{\gamma}+(1-\alpha) \frac{Y_{t}}{L_{t}}= \\
=\mu_{t}\left(1+\frac{V_{t}}{U_{t}}\right)-\beta E_{t} \frac{C_{t}}{C_{t+1}} \mu_{t+1}\left(1+\frac{V_{t+1}}{U_{t+1}}\right)\left(1-\delta_{L t+1}\right)
\end{array}
$$

Using equation (60) the Lagrange multiplier $\mu_{t}$ can be expressed as a function of the matching shock $B_{t}$ :

$$
\mu_{t}=\frac{\chi\left(L_{t}+U_{t}+V_{t}\right)^{\gamma}}{B_{t}\left(\frac{V_{t}}{U_{t}}\right)^{1-\theta}}
$$


Also the separation rate is connected to the matching shock through the labor accumulation equation (56):

$$
\left(1-\delta_{L t+1}\right)=\frac{L_{t+1}-B_{t+1} U_{t+1}^{\theta} V_{t+1}^{1-\theta}}{L_{t}}
$$

Then substituting equations (64) and (65) into equation (63) we obtain:

$$
\begin{gathered}
\left(\frac{1+\frac{V_{t}}{U_{t}}}{\left(\frac{V_{t}}{U_{t}}\right)^{1-\theta}} \frac{1}{B_{t}}-1\right) L_{t}=\frac{(1-\alpha) Y_{t}}{C_{t} \chi\left(L_{t}+U_{t}+V_{t}\right)^{\gamma}}+ \\
+\beta E_{t} \frac{C_{t}}{C_{t+1}} \frac{1+\frac{V_{t+1}}{U_{t+1}}}{\left(\frac{V_{t+1}}{U_{t+1}}\right)^{1-\theta}}\left(\frac{L_{t+1}+U_{t+1}+V_{t+1}}{L_{t}+U_{t}+V_{t}}\right)^{\gamma}\left[\frac{L_{t+1}}{B_{t+1}}-U_{t+1}^{\theta} V_{t+1}^{1-\theta}\right]
\end{gathered}
$$

Equation (66) provides a forward-looking equation for the matching shock $B_{t+1}$ as a function of $B_{t}$. Solving this equation recursively given some initial value $B_{0}$ we can recover the whole path for the matching shock. Then equation (65) allows us to back up the separation rate, equations (61) and (60) allow us to calculate the Lagrange multipliers $\mu_{t}$ and $\eta_{t}$. Then from equation (62) we can compute the bargaining shock $\phi_{t}$.

Altogether equations (54-62) describe a one-to-one mapping between the data and the underlying shocks. However the algorithm described here is hard to implement directly for two reasons. First, the equations are forward looking and can only be solved under certain assumptions about expectation formation. Second, many of the parameters of the model are unknown and cannot be simply calibrated from microeconomic data. That is the reason why we postulate stochastic processes for the shocks, linearize the model around a steady-state to compute an approximate solution and use Kalman filter to recover the underlying processes for the shocks.

\section{A.2 Appendix B}

\section{A.2.1 The Detrended Model}

Once we detrend all the variables of the model, we come to the following representation: 


$$
\begin{aligned}
& E_{t} \psi_{t+1}\left(\alpha \frac{y_{t+1}}{k_{t+1}}-\frac{1-\delta_{K}}{\tau_{t+1}}\right)=1 \\
& y_{t}=a_{t} k_{t}^{\alpha} L_{t}^{1-\alpha} \\
& c_{t}+z_{t} k_{t+1}-\left(1-\delta_{K}\right) \frac{k_{t}}{\tau_{t}}+g_{t}=y_{t} \\
& \Gamma_{t}=\left((1-\alpha) \frac{y_{t}}{L_{t}}-\kappa_{t}\right)+E_{t} \psi_{t+1} \Gamma_{t+1}\left(1-\delta_{L t}\right) \\
& \left(B_{t} U_{t}^{\theta} V_{t}^{1-\theta}\right) \Gamma_{t}=\left(V_{t}+U_{t}\right) \kappa_{t} \\
& \phi_{t} V_{t}=\left(1-\phi_{t}\right) U_{t} \\
& L_{t}=\left(1-\delta_{L t}\right) L_{t-1}+B_{t} U_{t}^{\theta} V_{t}^{1-\theta} \\
& z_{t}^{1-\alpha}=a_{t} \tau_{t}^{\alpha} \\
& m_{t}=\left(1-\delta_{L t}\right) \frac{\Gamma_{t}}{\Gamma_{t-1}} \\
& \psi_{t}=\beta\left(\frac{c_{t-1}}{c_{t}}\right) \frac{1}{z_{t-1}} \\
& \kappa_{t}=\chi c_{t}\left(L_{t}+U_{t}+V_{t}\right)^{\gamma} \\
& q_{t}=\left(1-\phi_{t}\right) \Gamma_{t} B_{t}\left(\frac{U_{t}}{V_{t}}\right)^{\theta} \\
& \left(1-E_{t} m_{t+1} \psi_{t+1}\right)\left(w_{t}-\kappa_{t}\right)=\left(\phi_{t}-E_{t} m_{t+1} \psi_{t+1} \phi_{t+1}\right)\left((1-\alpha) \frac{y_{t}}{L_{t}}-\kappa_{t}\right) \\
& a_{t}=a_{s s} \exp \left(\sigma_{A t} \varepsilon_{A t}\right)
\end{aligned}
$$




$$
\tau_{t}=\tau_{s s} \exp \left(\sigma_{T t} \varepsilon_{T t}\right)
$$

$$
\begin{aligned}
& \log \delta_{L t}=\left(1-\rho_{S}\right) \log \delta_{L s s}+\rho_{S} \log \delta_{L t-1}+\sigma_{S} \varepsilon_{S t} \\
& \log B_{t}=\left(1-\rho_{M}\right) \log b_{s s}+\rho_{M} \log B_{t-1}+\sigma_{M} \varepsilon_{M t} \\
& \log \phi_{t}=\left(1-\rho_{B}\right) \log \phi_{s s}+\rho_{B} \log \phi_{t-1}+\sigma_{B} \varepsilon_{B t} \\
& \log g_{t}=\left(1-\rho_{G}\right) \log g_{s s} y_{s s}+\rho_{G} \log g_{t-1}+\sigma_{G} \varepsilon_{G t} \\
& d \log G D P_{t}=\log \frac{y_{t}+q_{t} V_{t}}{y_{t-1}+q_{t-1} V_{t-1}} z_{t-1} \\
& d \log \text { Cons }_{t}=\log \frac{c_{t}}{c_{t-1}} z_{t-1} \\
& d \log \operatorname{Inv}_{t}=\log \frac{k_{t+1} z_{t} \tau_{t}-\left(1-\delta_{K}\right) k_{t}}{k_{t} z_{t-1} \tau_{t-1}-\left(1-\delta_{K}\right) k_{t-1}} z_{t-1} \tau_{t-1} \\
& \text { Hours }_{t}=\frac{L_{t}+V_{t}}{L_{s s}+V_{s s}} \\
& U n e m p t=\frac{U_{t}}{L_{t}+V_{t}+U_{t}} \text {. } \\
& \text { HWant }_{t}=\frac{V_{t}}{V_{s s}}
\end{aligned}
$$

\section{A.2.2 Computing the Steady-State.}

Choose a value of $L_{s s}$
1) $\quad z_{s s}=\left(a_{s s} \tau_{s s}^{\alpha}\right)^{\frac{1}{1-\alpha}}$
2) Denote $\varphi=\left(\left(\frac{z_{s s}}{\beta}+\frac{1-\delta_{K}}{\tau_{s s}}\right) / \alpha a_{s s}\right)^{-\frac{1}{1-\alpha}}$
3) $k_{s s}=\varphi L_{s s} \quad y_{s s}=a_{s s} \varphi^{\alpha} L_{s s}$
4) $\quad c_{s s}=\left[\left(1-g_{s s}\right) a_{s s} \varphi^{\alpha}-\left(z_{s s}-\frac{\left(1-\delta_{K}\right)}{\tau_{s s}}\right) \varphi\right] L_{s s}$
5) $\quad B_{s s}=\frac{1}{\omega_{s s}}\left(\frac{\phi_{s s}}{1-\phi_{s s}}\right)^{1-\theta}$ 
6) $U_{s s}=\omega_{s s} \delta_{L} L_{s s} \quad V_{s s}=\frac{1-\phi_{s s}}{\phi_{s s}} U_{s s}$
7) $\xi=\frac{y_{s s}}{L_{s s} c_{s s}} \frac{1-\alpha}{\left(1+\frac{\omega_{s s}}{\phi_{s s}}\left(1-\frac{\beta}{z_{s s}}\left(1-\delta_{L}\right)\right)\right)}$

8) We have assumed a normalization $\chi=\frac{\xi}{\left(L_{s s}+U_{s s}+V_{s s}\right)^{\gamma}}$

9) $\kappa_{s s}=\xi c_{s s} \quad m_{s s}=1-\delta_{L}$

10) $\quad \Gamma_{s s}=\xi c_{s s} \frac{\omega_{s s}}{\phi_{s s}}$

11) $w_{s s}=\phi_{s s}(1-\alpha) \frac{y_{s s}}{L_{s s}}-\left(1-\phi_{s s}\right) \kappa_{s s}$

12) $\psi_{s s}=\frac{\beta}{z_{s s}} \quad q_{s s}=\kappa_{s s}$ 


\section{A.3 Appendix C}
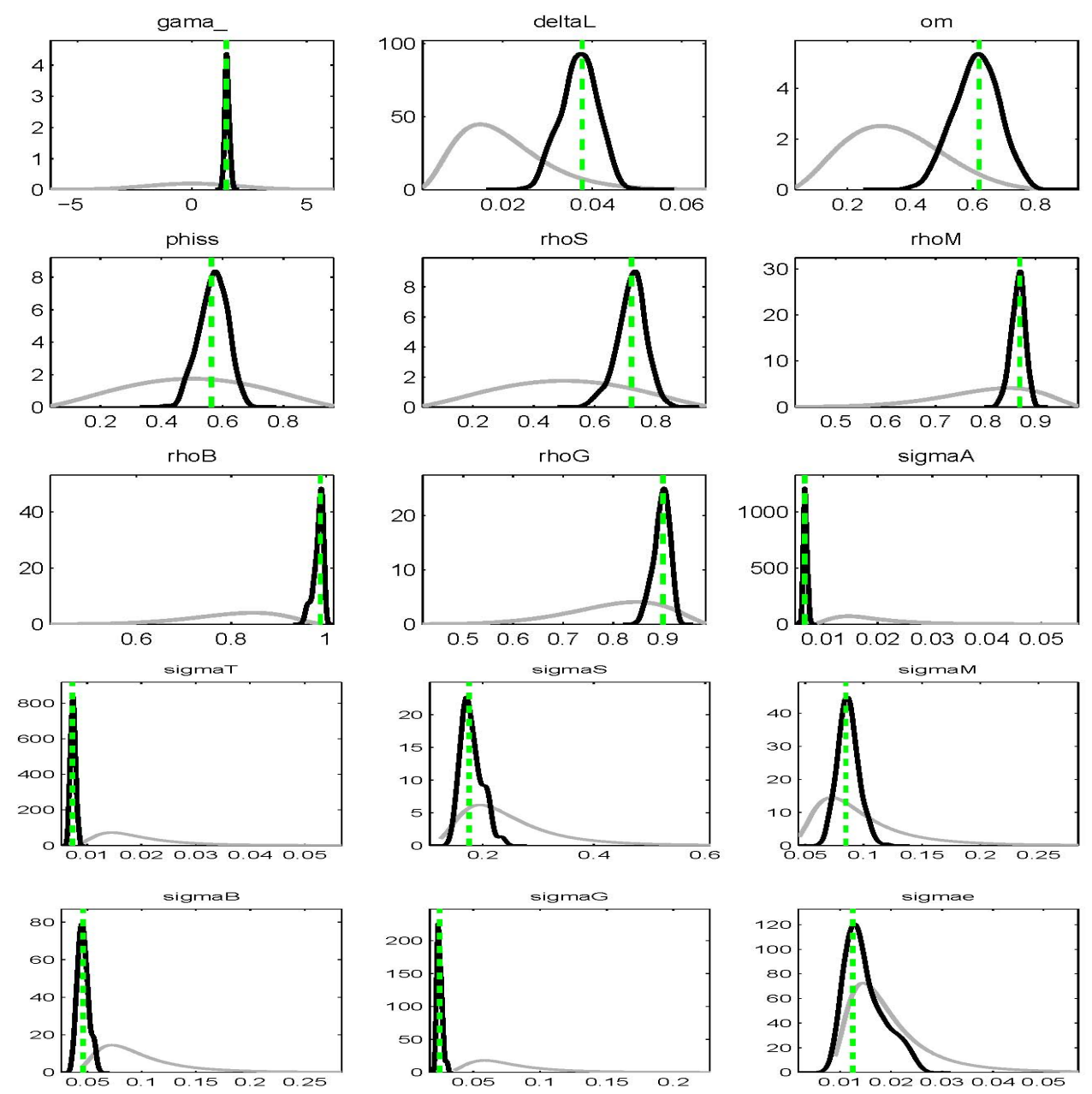

Figure 8: Prior (grey) and posterior (black) distributions of parameters 


\begin{tabular}{|c|c|c|c|}
\hline Wedge & Efficiency & Investment & Labor \\
\hline Output & 0.73 & 0.31 & 0.59 \\
\hline
\end{tabular}

Table 5: Ratios of standard deviations explained by each wedge. Source: Chari, Kehoe and McGrattan (2007)

\section{A.4 Appendix D}

\section{A.4.1 Comparison to CKM}

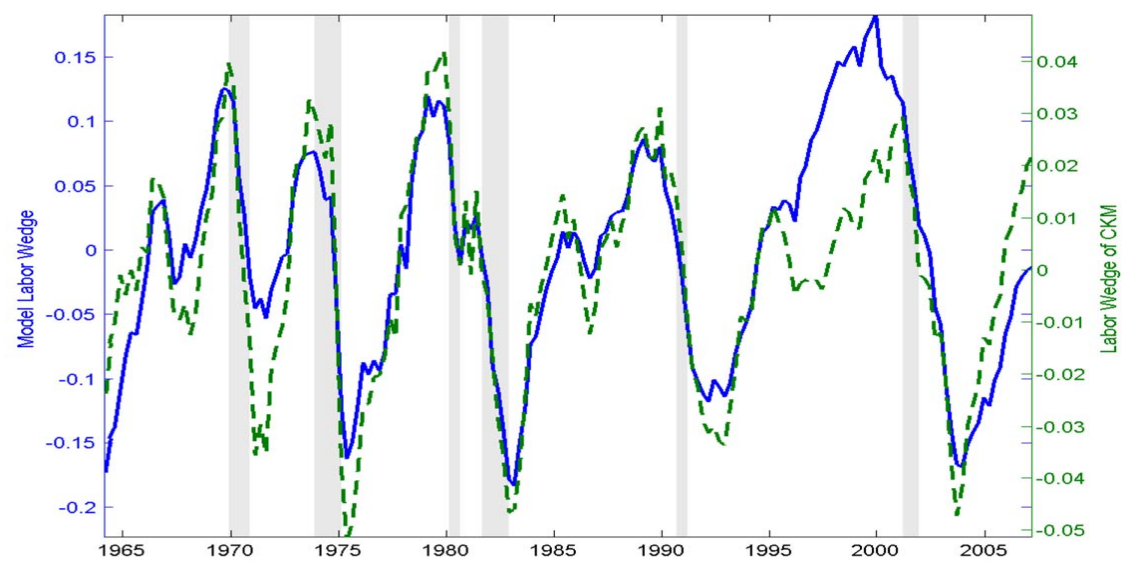

Figure 9: Comparison of the Labor Wedge to the Estimate of CKM

\section{A.4.2 Full Decompositions and Correlation Structure}

Table 5 reports the numbers from the original paper by Chari, Kehoe and McGrattan (2007). Comparing the second row of Tables 5 and 6 one can verify that our decompositions are comparable with those of CKM since the difference in the contributions of TFP, Investment and Labor shocks is insignificant. Table 6 also gives a clearer picture of the relative contributions of the labor shocks.

Table 7 reports the same fractions of standard deviations as Table 4, but averaged over a selection of recession periods. It demonstrates that during recessions the labor wedge and TFP play a slightly more important role in business cycles than in normal times, while the contribution of investment shocks is negligible both in recessions and overall. 


\begin{tabular}{|c|c|c|c|c|}
\hline Shock & TFP & Investment & Government & Labor \\
\hline \multirow{6}{*}{$\begin{array}{l}\text { Output } \\
\text { Consumption } \\
\text { Investment } \\
\text { Hours } \\
\text { Unemployment } \\
\text { Vacancies }\end{array}$} & 0.67 & 0.09 & 0.05 & 0.70 \\
\hline & 0.68 & 0.86 & 0.65 & 0.51 \\
\hline & 0.57 & 0.43 & 0.40 & 0.41 \\
\hline & 0.07 & 0.12 & 0.08 & 1.02 \\
\hline & 0.06 & 0.04 & 0.04 & 1.00 \\
\hline & 0.06 & 0.04 & 0.04 & 1.00 \\
\hline
\end{tabular}

\begin{tabular}{|c|c|c|c|c|}
\hline Shock & TFP & Separation & Matching & Bargaining \\
\hline \multirow{6}{*}{$\begin{array}{l}\text { Output } \\
\text { Consumption } \\
\text { Investment } \\
\text { Hours } \\
\text { Unemployment } \\
\text { Vacancies }\end{array}$} & 0.67 & 0.32 & 0.61 & 0.14 \\
\hline & 0.68 & 0.38 & 0.63 & 0.07 \\
\hline & 0.57 & 0.38 & 0.51 & 0.05 \\
\hline & 0.07 & 0.41 & 1.10 & 0.25 \\
\hline & 0.06 & 1.08 & 1.26 & 0.67 \\
\hline & 0.06 & 0.85 & 0.95 & 1.23 \\
\hline
\end{tabular}

Table 6: Ratios of standard deviations explained by each shock over the whole period (1964-2007)

\begin{tabular}{|c|c|c|c|c|}
\hline Shock & TFP & Investment & Government & Labor \\
\hline \multirow{6}{*}{$\begin{array}{l}\text { Output } \\
\text { Consumption } \\
\text { Investment } \\
\text { Hours } \\
\text { Unemployment } \\
\text { Vacancies }\end{array}$} & 0.76 & 0.08 & 0.05 & 0.71 \\
\hline & 0.71 & 0.87 & 0.66 & 0.48 \\
\hline & 0.68 & 0.47 & 0.48 & 0.42 \\
\hline & 0.05 & 0.05 & 0.06 & 1.02 \\
\hline & 0.04 & 0.02 & 0.03 & 0.99 \\
\hline & 0.05 & 0.03 & 0.03 & 1.01 \\
\hline
\end{tabular}

\begin{tabular}{|c|c|c|c|c|}
\hline Shock & TFP & Separation & Matching & Bargaining \\
\hline \multirow{6}{*}{$\begin{array}{l}\text { Output } \\
\text { Consumption } \\
\text { Investment } \\
\text { Hours } \\
\text { Unemployment } \\
\text { Vacancies }\end{array}$} & 0.76 & 0.34 & 0.62 & 0.16 \\
\hline & 0.71 & 0.36 & 0.56 & 0.19 \\
\hline & 0.68 & 0.48 & 0.52 & 0.06 \\
\hline & 0.05 & 0.28 & 0.82 & 0.31 \\
\hline & 0.04 & 0.48 & 0.57 & 0.60 \\
\hline & 0.05 & 0.60 & 0.68 & 1.41 \\
\hline
\end{tabular}

Table 7: Ratios of standard deviations explained by each shock averaged over 5 recessions $(70,75,82,91,01)$ 


\begin{tabular}{|l|c|c|c|c|c|}
\hline & \multicolumn{5}{|c|}{ Correlation of X with Y at lag k } \\
\hline Shocks $(\mathrm{X}, \mathrm{Y})$ & -2 & -1 & 0 & 1 & 2 \\
\hline TFP, Investment & -0.70 & -0.68 & -0.61 & -0.58 & -0.54 \\
\cline { 2 - 6 } TFP, Government & 0.08 & 0.03 & -0.01 & -0.04 & -0.06 \\
\cline { 2 - 6 } Investment, Government & -0.14 & -0.16 & -0.15 & -0.13 & -0.10 \\
\cline { 2 - 6 } TFP, Separation & -0.44 & -0.45 & -0.44 & -0.39 & -0.29 \\
\cline { 2 - 6 } TFP, Matching & -0.39 & -0.31 & -0.21 & -0.12 & -0.00 \\
\cline { 2 - 6 } TFP, Bargaining & 0.26 & 0.11 & -0.02 & -0.15 & -0.26 \\
\cline { 2 - 6 } Separation, Bargaining & 0.89 & 0.85 & 0.72 & 0.57 & 0.43 \\
\cline { 2 - 6 } Separation, Matching & -0.77 & -0.68 & -0.55 & -0.39 & -0.25 \\
\cline { 2 - 6 } Bargaining, Matching & -0.72 & -0.83 & -0.89 & -0.90 & -0.85 \\
\hline
\end{tabular}

Table 8: Cross Correlations of Shocks and Their Lags

Table 8 reports cross correlations of shocks at different lags confirming the picture of TFP and separation shocks starting recessions and bargaining and matching shocks coming into play only later on.

\section{A.5 Appendix E}

Figure 10 demonstrates the emphasized decomposition of unemployment for previous four recession episodes: separations create the initial pool of unemployed, and adverse matching shocks slow down the recovery.

Figure 11 shows that if there was no change in the labor wedge, the recession would have been much shorter (if at all noticeable) and half as severe. If there was no change in total factor productivity, the recession probably wouldn't have started. Absence of investment shocks would have almost no effect on the path of output. Thus the TFP shock is at work mostly at the start of the recession of 2001. The labor wedge explains the bulk of fluctuations in output after the recession has started.

Figure 12 shows that matching shocks are the main source of declines in the number of hours worked. Figure 13 demonstrates that bargaining shocks are the main source of declines in the number of vacancies during the 2001 recession. 

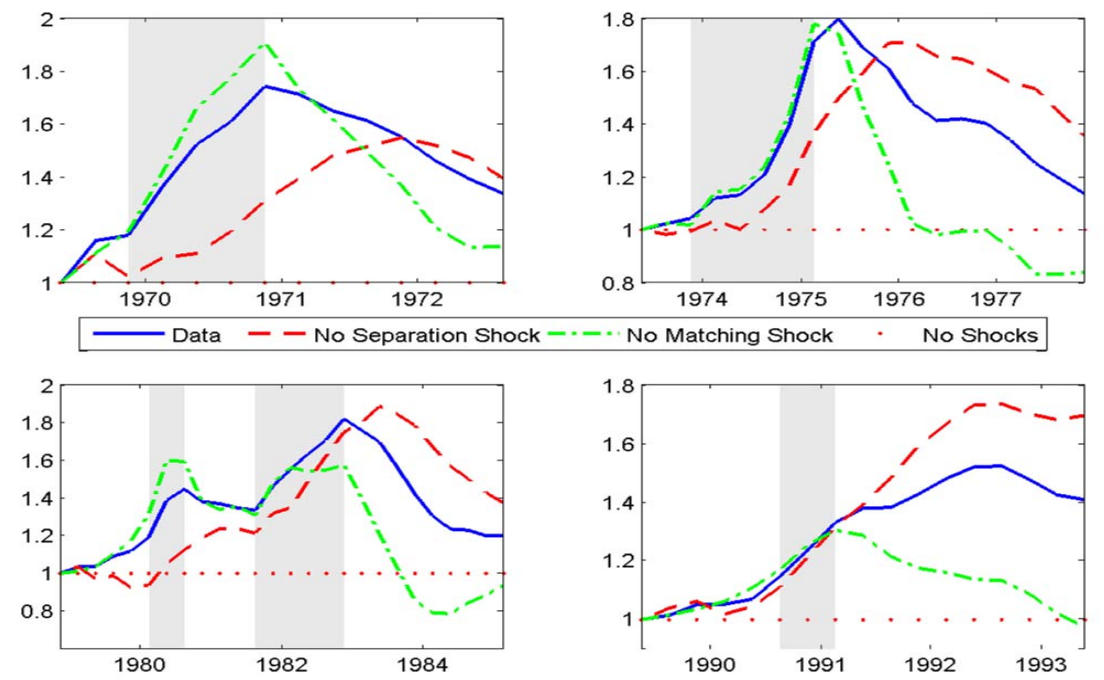

Figure 10: Effects of separation and matching shocks on unemployment

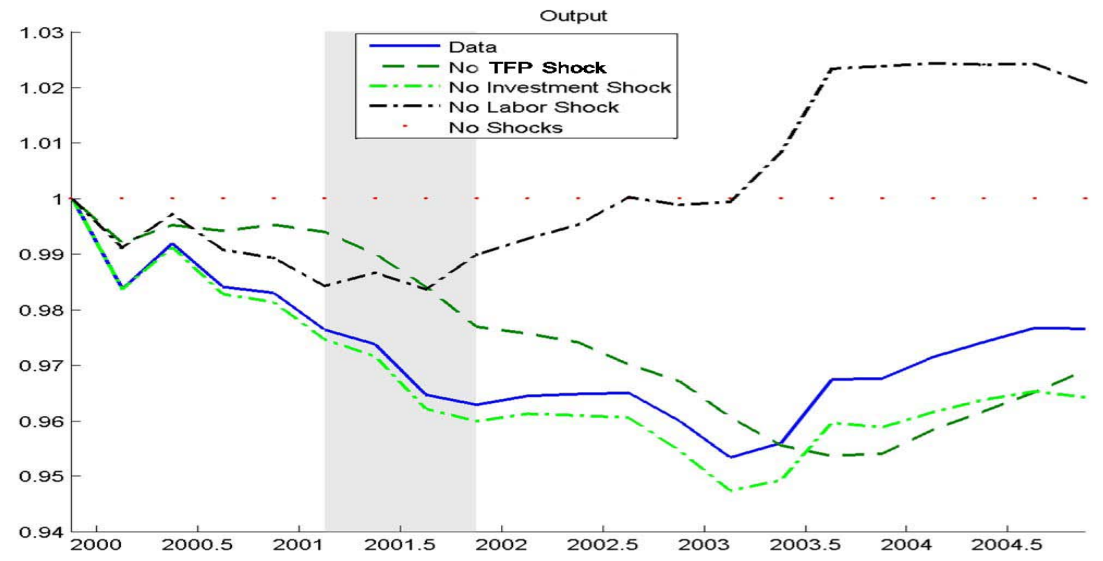

Figure 11: Output with all but one shock 


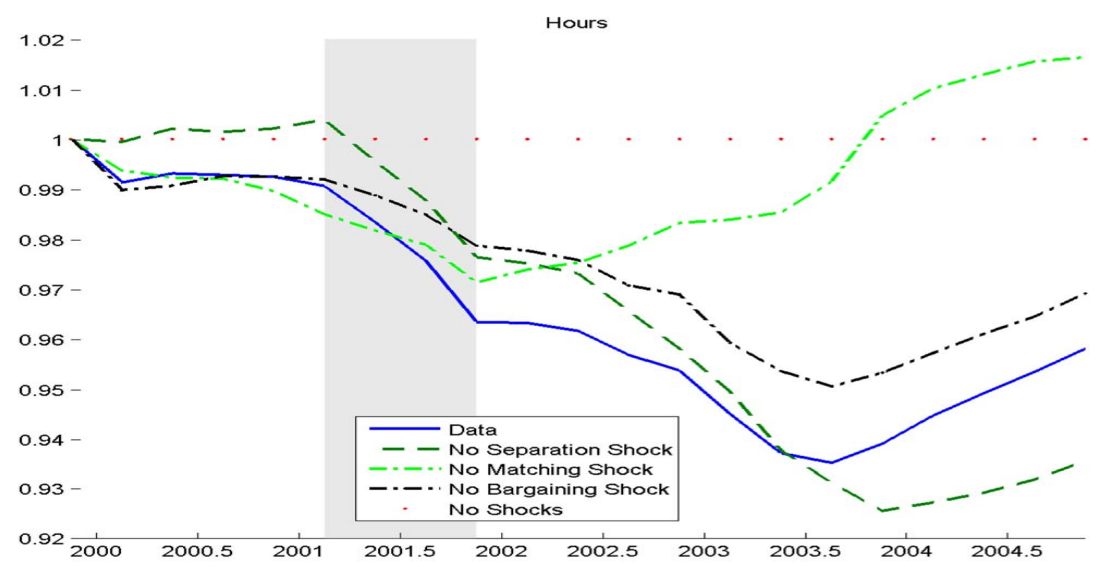

Figure 12: Hours with all but one shock

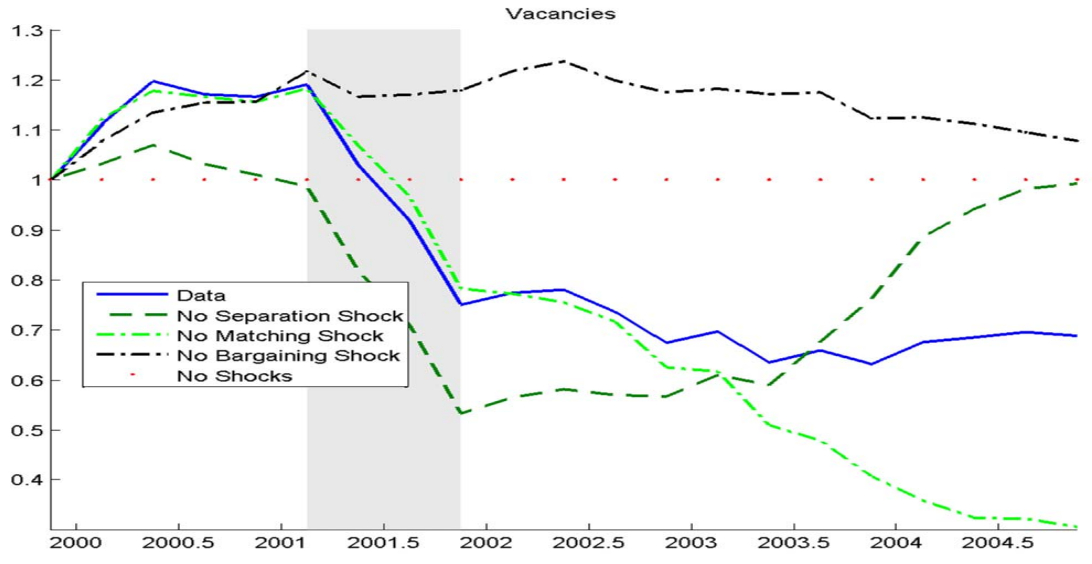

Figure 13: Vacancies with all but one shock 